\title{
Mild and Efficient Lewis Acid-Promoted Detritylation in the Synthesis of $N$-Hydroxy Amides: A Concise Synthesis of (-)-Cobactin T
}

\author{
Shyh-Ming Yang, * Bharat Lagu, Lawrence J. Wilson
}

Johnson \& Johnson Pharmaceutical Research and Development, L.L.C.

8 Clarke Drive, Cranbury, NJ 08512, USA

Contents:

page

I. Preparation of Precursors for Detritylation................................. 52

II. Lewis Acid Promoted Detritylation..................................... S11

III. Synthesis of (-)-Cobactin T........................................ S18

IV. NMR Spectra of Representative Compounds..............................S23 


\section{Preparation of Precursors for Detritylation}

Preparation of $\quad N$-Triphenylmethoxy 2-(9-fluorenylmethoxycarbonylamino)-4pentenoamide (1a).

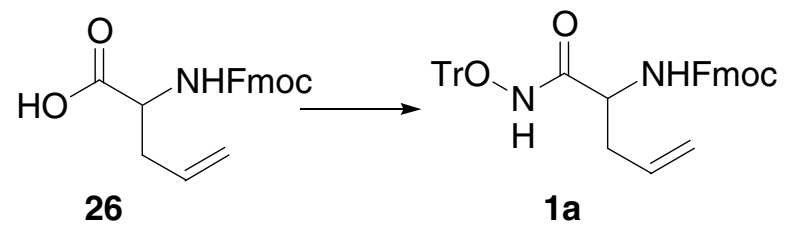

To a mixture of $N$-Fmoc-allylglycine 26 (6.74 g, $20 \mathrm{mmol})$, EDC (5.73 g, $30 \mathrm{mmol}, 1.5$ equiv), HOBt (2.97 g, $22 \mathrm{mmol}, 1.1$ equiv) and DMAP (2.68 g, $22 \mathrm{mmol}, 1.1$ equiv) in $\mathrm{CHCl}_{3}(100 \mathrm{~mL})$ was added $\mathrm{Et}_{3} \mathrm{~N}(4.18 \mathrm{~mL}, 30 \mathrm{mmol}, 1.5$ equiv) and then $O$-trityl hydroxylamine (6.88 g, $25 \mathrm{mmol}, 1.25$ equiv) sequentially at room temperature under $\mathrm{N}_{2}$. The mixture was stirred at $\mathrm{rt}$ for $6 \mathrm{~h}$ and was then poured into $\mathrm{CHCl}_{3} / \mathrm{H}_{2} \mathrm{O}(100 \mathrm{~mL} / 100$ $\mathrm{mL})$. The organic layer was separated and was washed with $\mathrm{H}_{2} \mathrm{O}(100 \mathrm{~mL}), 0.5 \mathrm{~N} \mathrm{HCl}_{(\mathrm{aq})}$ $(100 \mathrm{~mL}), \mathrm{H}_{2} \mathrm{O}(100 \mathrm{~mL})$, brine $(100 \mathrm{~mL})$, dried $\left(\mathrm{Na}_{2} \mathrm{SO}_{4}\right)$, and then filtered. After removal of solvent, $\mathrm{Et}_{2} \mathrm{O}(200 \mathrm{~mL})$ was added to the crude product. The white solid was filtered and was washed with $\mathrm{Et}_{2} \mathrm{O}(100 \mathrm{~mL})$. The solid was dried to give $10.2 \mathrm{~g}$ of $\mathbf{1 a}$ $(86 \%)$ as a white solid. ${ }^{1} \mathrm{H}$ NMR $\left(\mathrm{d}_{6}\right.$-DMSO, $\left.300 \mathrm{MHz}\right) \delta 10.54(\mathrm{~s}, 1 \mathrm{H}), 7.89$ (d, J = 6.0 $\mathrm{Hz}, 2 \mathrm{H}), 7.71(\mathrm{dd}, J=9.0,3.0 \mathrm{~Hz}, 2 \mathrm{H}), 7.42$ (t, $J=9.0 \mathrm{~Hz}, 2 \mathrm{H}), 7.35-7.24(\mathrm{~m}, 17 \mathrm{H})$, 5.50-5.43 (m, 1 H), 4.98 -4.91 (m, 2 H), 4.25-4.18 (m, 3 H), 3.94 (m, 1 H), 1.94-1.87 (m, $2 \mathrm{H}) .{ }^{13} \mathrm{C}$ NMR $\left(\mathrm{d}_{6}\right.$-DMSO, $\left.75 \mathrm{MHz}\right) \delta$ 169.1, 155.6, (143.82, 143.77), 142.2, 140.7, 134.1, 128.9, 127.6, 127.5, 127.4, 127.0, (125.35, 125.28), 120.1, 117.3, 92.0, 65.6, 51.6, 46.6, 35.8. MS (m/z) $617\left(\mathrm{M}^{+}+\mathrm{Na}, 10\right), 243$ (10), 179 (100), 174 (70), 157 (40). HRMS Calcd for $\mathrm{C}_{39} \mathrm{H}_{34} \mathrm{~N}_{2} \mathrm{O}_{4} \mathrm{Na}\left(\mathrm{M}^{+}+\mathrm{Na}\right)$ : 617.2416. Found: 617.2421.

Preparation of (1b).

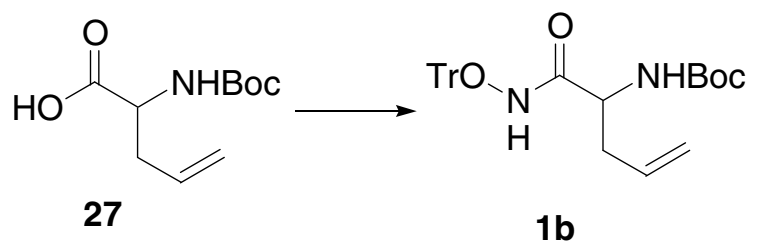

To a mixture of $N$-Boc-allylglycine 27 (2.15 g, $10 \mathrm{mmol})$, EDC (2.86 g, $15 \mathrm{mmol}, 1.5$ equiv), HOBt (1.48 g, $11 \mathrm{mmol}, 1.1$ equiv) and DMAP (1.83 g, $11 \mathrm{mmol}, 1.1$ equiv) in 
$\mathrm{CHCl}_{3}(50 \mathrm{~mL})$ was added $\mathrm{Et}_{3} \mathrm{~N}(2.1 \mathrm{~mL}, 15 \mathrm{mmol}, 1.5$ equiv $)$ and then $O$-trityl hydroxylamine ( $3.44 \mathrm{~g}, 12.5 \mathrm{mmol}, 1.25$ equiv) sequentially at room temperature under $\mathrm{N}_{2}$. The mixture was stirred at $\mathrm{rt}$ for $6 \mathrm{~h}$ and was then poured into $\mathrm{CHCl}_{3} / \mathrm{H}_{2} \mathrm{O}(100$ $\mathrm{mL} / 100 \mathrm{~mL})$. The organic layer was separated and was washed with $\mathrm{H}_{2} \mathrm{O}(100 \mathrm{~mL}), 0.5$ $\mathrm{N} \mathrm{HCl}_{(\mathrm{aq})}(100 \mathrm{~mL}), \mathrm{H}_{2} \mathrm{O}(100 \mathrm{~mL})$, brine $(100 \mathrm{~mL})$, dried $\left(\mathrm{Na}_{2} \mathrm{SO}_{4}\right)$, and then filtered. After removal of solvent, $\mathrm{Et}_{2} \mathrm{O}(40 \mathrm{~mL})$ and hexane $(120 \mathrm{~mL})$ were added sequentially to the crude product. The white solid was filtered and was washed with $\mathrm{Et}_{2} \mathrm{O} /$ hexane $(1 / 4$, $30 \mathrm{~mL}$ ). The solid was dried to give $3.73 \mathrm{~g}$ of $\mathbf{1 b}(79 \%)$ as a white solid. ${ }^{1} \mathrm{H}$ NMR $\left(\mathrm{d}_{6^{-}}\right.$ DMSO, $300 \mathrm{MHz}) \delta 10.37$ (s, $1 \mathrm{H}), 7.39-7.32(\mathrm{~m}, 15 \mathrm{H}), 6.58(\mathrm{~d}, J=8.1 \mathrm{~Hz}, 1 \mathrm{H}, \mathrm{NH})$, 5.48-5.39 (m, $1 \mathrm{H})$, 4.94-4.88 (m, $2 \mathrm{H}), 3.82$ (m, $1 \mathrm{H}), 1.87-1.82$ (m, $2 \mathrm{H}), 1.33$ (s, $9 \mathrm{H})$. ${ }^{13} \mathrm{C}$ NMR $\left(\mathrm{d}_{6}\right.$-DMSO, $\left.75 \mathrm{MHz}\right) \delta 167.4,154.7,140.8,132.0,128.0,127.0,126.8,117.9$, 92.2, 79.4, 50.6, 34.7, 27.3. MS ( $\mathrm{m} / z) 967\left(2 \mathrm{M}^{+}+\mathrm{Na}, 70\right), 495\left(\mathrm{M}^{+}+\mathrm{Na}, 15\right), 243(100)$. Anal. Calcd for $\mathrm{C}_{29} \mathrm{H}_{32} \mathrm{~N}_{2} \mathrm{O}_{4}$ : C, 73.70; H, 6.83; N, 5.93. Found: C, 73.46; H, 6.78; N, 5.86.

Preparation of (1c).

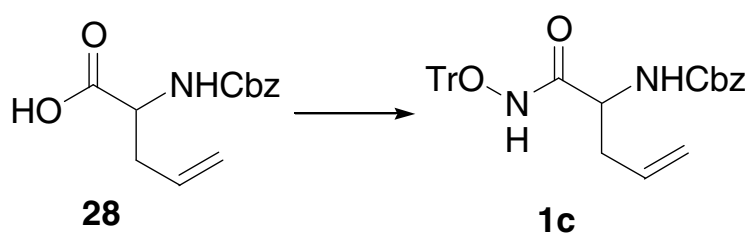

To a mixture of $N$-Cbz-allylglycine 28 (2.24 g, 9 mmol), EDC (2.58 g, $13.5 \mathrm{mmol}, 1.5$ equiv), HOBt (1.34 g, 9.9 mmol, 1.1 equiv) and DMAP (1.21 g, 9.9 mmol, 1.1 equiv) in $\mathrm{CHCl}_{3}(50 \mathrm{~mL})$ was added $\mathrm{Et}_{3} \mathrm{~N}(1.88 \mathrm{~mL}, 13.5 \mathrm{mmol}, 1.5$ equiv) and then $O$-trityl hydroxylamine ( $3.05 \mathrm{~g}, 11.25 \mathrm{mmol}, 1.25$ equiv) sequentially at room temperature under $\mathrm{N}_{2}$. The mixture was stirred at $\mathrm{rt}$ for $6 \mathrm{~h}$ and was then poured into $\mathrm{CHCl}_{3} / \mathrm{H}_{2} \mathrm{O}(100$ $\mathrm{mL} / 100 \mathrm{~mL})$. The organic layer was separated and was washed with $\mathrm{H}_{2} \mathrm{O}(100 \mathrm{~mL}), 0.5$ $\mathrm{N} \mathrm{HCl}_{(\mathrm{aq})}(100 \mathrm{~mL}), \mathrm{H}_{2} \mathrm{O}(100 \mathrm{~mL})$, brine $(100 \mathrm{~mL})$, dried $\left(\mathrm{Na}_{2} \mathrm{SO}_{4}\right)$, and then filtered. After removal of solvent, $\mathrm{Et}_{2} \mathrm{O}(40 \mathrm{~mL})$ and hexane $(120 \mathrm{~mL})$ were added sequentially to the crude product. The white solid was filtered and was washed with $\mathrm{Et}_{2} \mathrm{O} /$ hexane $(1 / 4$, $50 \mathrm{~mL})$. The solid was dried to give $3.68 \mathrm{~g}$ of $1 \mathrm{c}(81 \%)$ as a white solid. ${ }^{1} \mathrm{H}$ NMR $\left(\mathrm{d}_{6^{-}}\right.$ DMSO, $300 \mathrm{MHz}) \delta 10.54$ (s, $1 \mathrm{H}), 7.39-7.25(\mathrm{~m}, 20 \mathrm{H}), 7.19$ (d, $J=9.0 \mathrm{~Hz}, 1 \mathrm{H}, \mathrm{NH}$ ), 5.47-5.41 (m, 1 H), 5.04-4.90 (m, 4 H), 4.00-3.90 (m, 1 H), 1.91-1.80 (m, 2 H). MS (m/z) 
$529\left(\mathrm{M}^{+}+\mathrm{Na}, 35\right), 243$ (100). Anal. Calcd for $\mathrm{C}_{32} \mathrm{H}_{30} \mathrm{~N}_{2} \mathrm{O}_{4}$ : C, 75.87; H, 5.97; N, 5.53. Found: C, 75.56; H, 5.74; N, 5.52.

Preparation of (2).

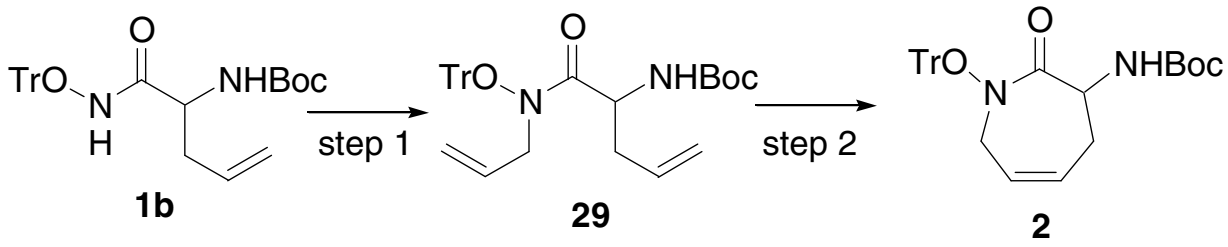

\section{Step 1:}

In a three-necked flask was placed $\mathbf{1 b}(7.08 \mathrm{~g}, 15 \mathrm{mmol})$. The air was removed and was refilled with $\mathrm{N}_{2}$ for three times. Then, dried $\mathrm{MeCN}$ (60 mL), allyl methyl carbonate (3.4 $\mathrm{mL}, 30 \mathrm{mmol}, 2$ equiv), and $\mathrm{Pd}\left(\mathrm{PPh}_{3}\right)_{4}(347 \mathrm{mg}, 0.3 \mathrm{mmol}, 0.02$ equiv) were added sequentially at room temperature under $\mathrm{N}_{2}$. The mixture was stirred at $\mathrm{rt}$ for $30 \mathrm{~min}$ and was then poured into a mixture of EtOAc $(150 \mathrm{~mL})$ and brine $(150 \mathrm{~mL})$. The organic layer was separated, dried $\left(\mathrm{Na}_{2} \mathrm{SO}_{4}\right)$, and filtered. After removal of solvent, the crude mixture was purified by silica gel chromatography using EtOAc/hexane (1/9 to 1/4) as the eluent to give $6.91 \mathrm{~g}$ of $29(90 \%)$ as a colorless oil. ${ }^{1} \mathrm{H}$ NMR $\left(\mathrm{CDCl}_{3}, 300 \mathrm{MHz}\right) \delta$ 7.43-7.25 (m, 15 H), 5.80-5.60 (m, 2 H), 5.24-5.05 (m, 4 H), 4.90 (d, J = 7.5 Hz, $1 \mathrm{H})$, 4.49-4.44 (m, 1 H), 4.29-4.22 (m, 1 H), 3.60-3.50 (m, 1 H), 2.50-2.40 (m, 1 H), 2.30-2.20 $(\mathrm{m}, 1 \mathrm{H}), 1.37$ (s, $9 \mathrm{H}) .{ }^{13} \mathrm{C} \mathrm{NMR}\left(\mathrm{CDCl}_{3}, 75 \mathrm{MHz}\right) \delta 174.0,154.1,141.8,133.1,132.0$, 129.6, 128.1, 127.9, 118.5, 118.1, 94.8, 78.7, 50.5, 50.1, 37.2, 28.3. MS (m/z) 1047 $\left(2 \mathrm{M}^{+}+\mathrm{Na}, 20\right), 535\left(\mathrm{M}^{+}+\mathrm{Na}, 10\right), 243$ (100). Anal. Calcd for $\mathrm{C}_{32} \mathrm{H}_{36} \mathrm{~N}_{2} \mathrm{O}_{4}: \mathrm{C}, 74.97 ; \mathrm{H}$, 7.08; N, 5.46. Found: C, 74.61; H, 7.11; N, 5.37.

\section{Step 2:}

In a three-necked flask was placed $29(3.07 \mathrm{~g}, 6.0 \mathrm{mmol})$. The air was removed and was refilled with $\mathrm{N}_{2}$ for three times. $\mathrm{CH}_{2} \mathrm{Cl}_{2}(240 \mathrm{~mL})$ and Grubbs II catalyst (246 mg, 0.3 mmol, 0.05 equiv) were added sequentially. The mixture was stirred at $40{ }^{\circ} \mathrm{C}$ for $16 \mathrm{~h}$. The mixture was then stirred at $\mathrm{rt} 1 \mathrm{~h}$ under air. The mixture was filtered through silica gel $(70 \mathrm{~g})$ and was eluted with $\mathrm{CH}_{2} \mathrm{Cl}_{2}(50 \mathrm{~mL})$ then EtOAc/hexane $(7 / 13,300 \mathrm{~mL})$. The EtOAc/hexane filtrate was collected and the solvent was removed. The crude mixture 
was purified by silica gel chromatography using EtOAc/hexane (1/9 to 1/4) as the eluent to give $2.38 \mathrm{~g}$ of $2(82 \%)$ as a sticky oil. ${ }^{1} \mathrm{H} \mathrm{NMR}\left(\mathrm{CDCl}_{3}, 300 \mathrm{MHz}\right) \delta 7.46-7.38(\mathrm{~m}, 6$ H), 7.33-7.26 (m, 9 H), 5.65-5.58 (m, 1 H), 5.50-5.43 (m, 2 H), 4.41-4.26 (m, 2 H), 3.81 $(\mathrm{dd}, J=18.0,7.8 \mathrm{~Hz}, 1 \mathrm{H}), 2.40(\mathrm{dd}, J=18.0,3.6 \mathrm{~Hz}, 1 \mathrm{H}), 1.86(\mathrm{td}, J=15.0,2.4 \mathrm{~Hz}, 1$ $\mathrm{H}), 1.38$ (s, $9 \mathrm{H}) .{ }^{13} \mathrm{C} \mathrm{NMR}\left(\mathrm{CDCl}_{3}, 75 \mathrm{MHz}\right) \delta 170.8,155.0,142.5,130.0,129.9,127.9$, 127.4, 122.6, 94.4, 79.5, 51.1, 49.7, 32.8, 28.3. MS (m/z) $507\left(\mathrm{M}^{+}+\mathrm{Na}, 10\right), 485\left(\mathrm{M}^{+}+1\right.$, 5), 243 (100). Anal. Calcd for $\mathrm{C}_{30} \mathrm{H}_{32} \mathrm{~N}_{2} \mathrm{O}_{4}$ : C, 74.36; H, 6.66; N, 5.78. Found: C, 74.14; $\mathrm{H}, 6.71 ; \mathrm{N}, 5.60$.

Preparation of (3).
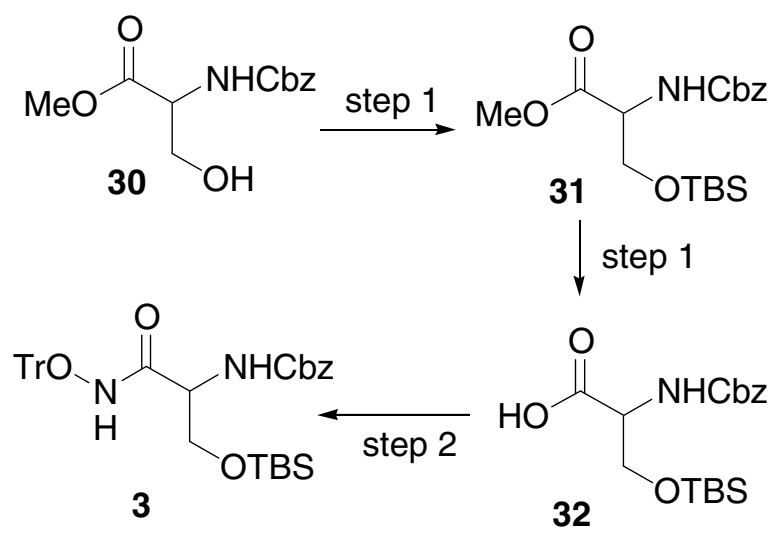

\section{Step 1:}

To a mixture of $30(7.590 \mathrm{~g}, 30 \mathrm{mmol})$ in DMF $(15 \mathrm{~mL})$ was added pyridine $(3.64 \mathrm{~mL}, 45$ $\mathrm{mmol})$ and then $\mathrm{TBS}-\mathrm{Cl}(5.4 \mathrm{~g}, 36 \mathrm{mmol})$ sequentially at $0{ }^{\circ} \mathrm{C}$ under $\mathrm{N}_{2}$. The mixture was then stirred at $\mathrm{rt}$ for $2.5 \mathrm{~h}$ and was poured into $\mathrm{Et}_{2} \mathrm{O} / \mathrm{H}_{2} \mathrm{O}(150 \mathrm{~mL} / 100 \mathrm{~mL})$. The organic layer was washed with $\mathrm{H}_{2} \mathrm{O}(100 \mathrm{~mL}), 1 \mathrm{~N} \mathrm{HCl}_{(\mathrm{aq})}(100 \mathrm{~mL}), \mathrm{H}_{2} \mathrm{O}(100 \mathrm{~mL})$, brine $(100$ $\mathrm{mL})$, dried $\left(\mathrm{Na}_{2} \mathrm{SO}_{4}\right)$ and filtered. After removal of solvent, the crude product was dissolved in THF $(30 \mathrm{~mL})$ and $1 \mathrm{~N} \mathrm{LiOH}_{(\mathrm{aq})}(60 \mathrm{~mL})$ was then added. The mixture was stirred at $\mathrm{rt}$ for $2 \mathrm{~h}$ and was poured into EtOAc/ $\mathrm{H}_{2} \mathrm{O}(150 \mathrm{~mL} / 100 \mathrm{~mL}) .2 \mathrm{~N} \mathrm{HCl}_{(\mathrm{aq})}(40$ $\mathrm{mL})$ was added. The organic layer was washed with $\mathrm{H}_{2} \mathrm{O}(100 \mathrm{~mL})$, brine $(100 \mathrm{~mL})$, dried $\left(\mathrm{Na}_{2} \mathrm{SO}_{4}\right)$, and filtered. After removal of solvent, the product was dried in vacuo to give $9.51 \mathrm{~g}$ of acid intermediate 32 (90\%, 2 steps), which was subjected to next reaction without further purification. ${ }^{1} \mathrm{H} \mathrm{NMR}\left(\mathrm{CDCl}_{3}, 400 \mathrm{MHz}\right) \delta 10.50-9.00$ (br s, $\left.1 \mathrm{H}\right), 7.33-$ $7.28(\mathrm{~m}, 5 \mathrm{H}), 5.56(\mathrm{~d}, J=6.0 \mathrm{~Hz}, 1 \mathrm{H}, \mathrm{NH}), 5.12-5.05$ (m, $2 \mathrm{H}), 4.43-4.41$ (m, $1 \mathrm{H}), 4.09$ 
$(\mathrm{dd}, J=9.0,3.0 \mathrm{~Hz}, 1 \mathrm{H}), 3.82(\mathrm{dd}, J=9.0,3.0 \mathrm{~Hz}, 1 \mathrm{H}), 0.82(\mathrm{~s}, 9 \mathrm{H}),-0.01(\mathrm{~s}, 6 \mathrm{H}) .{ }^{13} \mathrm{C}$ $\mathrm{NMR}\left(\mathrm{CDCl}_{3}, 100 \mathrm{MHz}\right) \delta 175.5,156.2,136.1,128.6,128.7,128.2,67.3,63.5,55.8$, $25.8,18.2,-5.53,-5.59$.

\section{Step 2:}

To a mixture of the acid intermediate 32 (7.06 g, $20 \mathrm{mmol})$, EDC ( $5.73 \mathrm{~g}, 30 \mathrm{mmol}, 1.5$ equiv), HOBt (4.05 g, $30 \mathrm{mmol}, 1.5$ equiv) and DMAP (3.66 g, $30 \mathrm{mmol}, 1.5$ equiv) in $\mathrm{CHCl}_{3}\left(100 \mathrm{~mL}\right.$ ) was added $\mathrm{Et}_{3} \mathrm{~N}(4.18 \mathrm{~mL}, 30 \mathrm{mmol}, 1.5$ equiv) and then $O$-trityl hydroxylamine ( $6.88 \mathrm{~g}, 25 \mathrm{mmol}, 1.25$ equiv) sequentially at room temperature under $\mathrm{N}_{2}$. The mixture was stirred at rt for $4 \mathrm{~h}$ and was then poured into $\mathrm{CHCl}_{3} / \mathrm{H}_{2} \mathrm{O}(100$ $\mathrm{mL} / 100 \mathrm{~mL})$. The organic layer was separated and was washed with $\mathrm{H}_{2} \mathrm{O}(100 \mathrm{~mL}), 0.5$ $\mathrm{N} \mathrm{HCl}_{(\mathrm{aq})}(100 \mathrm{~mL}), \mathrm{H}_{2} \mathrm{O}(100 \mathrm{~mL})$, brine $(100 \mathrm{~mL})$, dried $\left(\mathrm{Na}_{2} \mathrm{SO}_{4}\right)$, and then filtered. After removal of solvent, $\mathrm{Et}_{2} \mathrm{O}(40 \mathrm{~mL})$ and hexane $(120 \mathrm{~mL})$ were added sequentially to the crude product. The product was purified by silica gel chromatography using EtOAc/hexane (1/9 to $3 / 7)$ as the eluent to give $9.88 \mathrm{~g}$ of $\mathbf{3}(81 \%)$ as a white solid. ${ }^{1} \mathrm{H}$ NMR $\left(\mathrm{CDCl}_{3}, 400 \mathrm{MHz}\right) \delta 8.46$ (s, $\left.1 \mathrm{H}\right), 7.45-7.15$ (m, $20 \mathrm{H}$ ), 5.41 (br s, $\left.1 \mathrm{H}, \mathrm{NH}\right)$, 5.07$5.04(\mathrm{~m}, 2 \mathrm{H}), 3.91$ (dd, $J=9.0,6.0 \mathrm{~Hz}, 1 \mathrm{H}), 3.81(\mathrm{dd}, J=9.0,3.0 \mathrm{~Hz}, 1 \mathrm{H}), 3.39$ (t, $J=$ $6.0 \mathrm{~Hz}, 1 \mathrm{H}), 0.78$ (s, $9 \mathrm{H}),-0.02$ (s, $3 \mathrm{H}),-0.04$ (s, $3 \mathrm{H})$. MS (m/z) $633\left(\mathrm{M}^{+}+\mathrm{Na}, 20\right), 611$ $\left(\mathrm{M}^{+}+1,50\right), 243(100)$.

Preparation of (4)

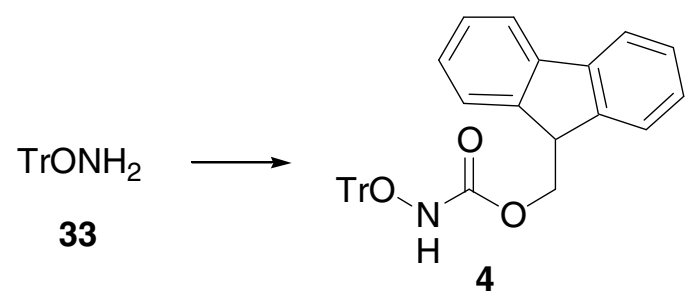

To a solution of 33 (1.51 g, $5.5 \mathrm{mmol}, 1.1$ equiv) in 1,4-dioxane (10 mL) was added saturated $\mathrm{NaHCO}_{3(\mathrm{aq})}(10 \mathrm{~mL})$ and the $\mathrm{Fmoc}-\mathrm{Cl}(1.293 \mathrm{~g}, 5.0 \mathrm{mmol})$ at room temperature. The mixture was stirred at $\mathrm{rt}$ for $3 \mathrm{~h}$ and was poured into EtOAc/hexane/ $\mathrm{H}_{2} \mathrm{O}(50 \mathrm{~mL} / 50$ $\mathrm{mL} / 50 \mathrm{~mL})$. The resulting white solid was filtered and was washed $\mathrm{H}_{2} \mathrm{O}(20 \mathrm{~mL})$ and $\mathrm{Et}_{2} \mathrm{O} /$ hexane $(1 / 4,20 \mathrm{~mL})$. The solid was dried to give $2.29 \mathrm{~g}$ of $\mathbf{4}(92 \%)$ as a white solid. 
${ }^{1} \mathrm{H}$ NMR (d ${ }_{6}$-DMSO, $\left.300 \mathrm{MHz}\right) \delta 9.99$ (s, $\left.1 \mathrm{H}\right), 7.87$ (d, $\left.J=7.5 \mathrm{~Hz}, 2 \mathrm{H}\right), 7.56$ (d, $J=7.5$ $\mathrm{Hz}, 2 \mathrm{H}), 7.40$ (t, $J=7.5 \mathrm{~Hz}, 2 \mathrm{H}), 7.34-7.26(\mathrm{~m}, 17 \mathrm{H}), 4.00-3.94$ (m, $3 \mathrm{H}) .{ }^{13} \mathrm{C}$ NMR $\left(\mathrm{d}_{6}\right.$-DMSO, $\left.100 \mathrm{MHz}\right) \delta 157.2,143.5,142.4,140.6,(129.1,128.9), 127.6,127.4,127.3$, (127.1, 126.9), (125.2, 125.1), 120.1, 91.8, (66.3, 65.9), 46.2. MS ( $/ 2 / z) 1017\left(2 \mathrm{M}^{+}+\mathrm{Na}\right.$, 15), $520\left(\mathrm{M}^{+}+\mathrm{Na}, 50\right), 243(100)$. HRMS Calcd for $\mathrm{C}_{34} \mathrm{H}_{27} \mathrm{NO}_{3} \mathrm{Na}\left(\mathrm{M}^{+}+\mathrm{Na}\right)$ : 520.1889 . Found: 520.1893.

Preparation of (5)

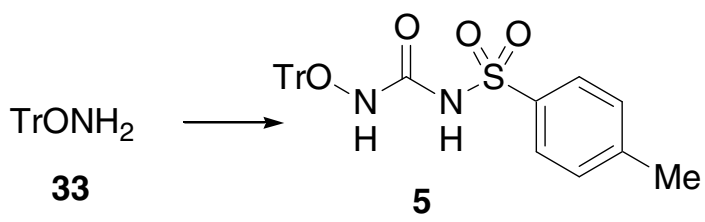

To a solution of 33 (1.91 g, $5.5 \mathrm{mmol}, 1.1$ equiv) in $\mathrm{MeCN}(15 \mathrm{~mL})$ was added $\mathrm{Et}_{3} \mathrm{~N}$ (0.7 $\mathrm{mL}, 5.0 \mathrm{mmol})$ and then 4-toluenesulfonyl isocyanate $(0.76 \mathrm{~mL}, 5.0 \mathrm{mmol})$ dropwise at room temperature. The mixture was stirred at $\mathrm{rt}$ for $2 \mathrm{~h}$ and was poured into EtOAc/ $\mathrm{H}_{2} \mathrm{O}$ $(50 \mathrm{~mL} / 50 \mathrm{~mL}) .2 \mathrm{~N} \mathrm{HCl}_{(\mathrm{aq})}(5 \mathrm{~mL})$ was then added. The organic layer was washed with $\mathrm{H}_{2} \mathrm{O}(50 \mathrm{~mL} \times 2)$, brine $(50 \mathrm{~mL})$, dried $\left(\mathrm{Na}_{2} \mathrm{SO}_{4}\right)$, and filtered. After removal of solvent, $\mathrm{Et}_{2} \mathrm{O}(15 \mathrm{~mL})$ and hexane $(150 \mathrm{~mL})$ was added sequentially to the crude mixture. The resulting solid was filtered and was washed with $\mathrm{Et}_{2} \mathrm{O} /$ hexane $(1 / 19,30 \mathrm{~mL})$ and then dried to give $1.95 \mathrm{~g}$ of $\mathbf{5}(83 \%)$ as a white solid. ${ }^{1} \mathrm{H}$ NMR ( $\mathrm{d}_{6}$-acetone, $\left.300 \mathrm{MHz}\right) \delta 8.80$ 8.60 (br s, $1 \mathrm{H}), 8.68$ (s, $1 \mathrm{H}), 7.64$ (d, $J=9.0 \mathrm{~Hz}, 2 \mathrm{H}), 7.42-7.25$ (m, $17 \mathrm{H}), 2.46$ (s, 3H). MS $(m / z) 967\left(2 \mathrm{M}^{+}+\mathrm{Na}, 85\right), 495\left(\mathrm{M}^{+}+\mathrm{Na}, 15\right), 243(100)$. Anal. Calcd for $\mathrm{C}_{27} \mathrm{H}_{24} \mathrm{~N}_{2} \mathrm{O}_{4} \mathrm{~S}$ : C, 68.62; H, 5.12; N, 5.93. Found: C, 68.02; H, 5.54; N, 5.40.

Preparation of $(\mathbf{6})$

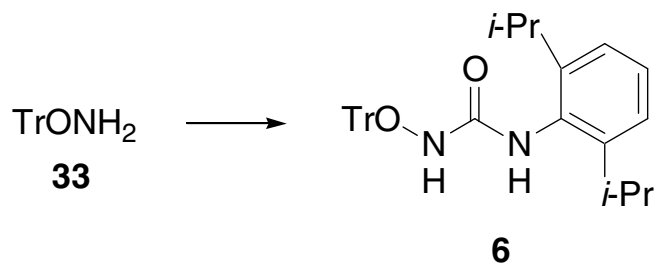

To a solution of 33 (1.91 g, $5.5 \mathrm{mmol}, 1.1$ equiv) in $\mathrm{MeCN}(15 \mathrm{~mL})$ was added $\mathrm{Et}_{3} \mathrm{~N}$ (0.7 $\mathrm{mL}, 5.0 \mathrm{mmol})$ and then 2,6-diisopropylphenyl isocyanate $(1.03 \mathrm{~mL}, 5.0 \mathrm{mmol})$ dropwise at room temperature. The mixture was stirred at $\mathrm{rt}$ for $4 \mathrm{~h}$ and was poured into a stirring 
mixture of hexane $/ \mathrm{H}_{2} \mathrm{O}(50 \mathrm{~mL} / 50 \mathrm{~mL})$. The resulting solid was filtered and was washed with $\mathrm{Et}_{2} \mathrm{O} /$ hexane $(1 / 4,30 \mathrm{~mL})$ and then dried to give $1.62 \mathrm{~g}$ of $\mathbf{6}(68 \%)$ as a white solid. ${ }^{1} \mathrm{H}$ NMR $\left(\mathrm{CDCl}_{3}, 300 \mathrm{MHz}\right) \delta$ 7.44-7.34 (m, $\left.15 \mathrm{H}\right), 7.22$ (t, $\left.J=6.0 \mathrm{~Hz}, 1 \mathrm{H}\right), 7.08(\mathrm{~d}, J=$ $7.5 \mathrm{~Hz}, 1 \mathrm{H}), 7.06(\mathrm{~d}, J=6.0 \mathrm{~Hz}, 1 \mathrm{H}), 6.43(\mathrm{~s}, 1 \mathrm{H}), 2.70-2.61(\mathrm{~m}, 2 \mathrm{H}), 1.10(\mathrm{~d}, J=6.0$ $\mathrm{Hz}, 12 \mathrm{H}) .{ }^{13} \mathrm{C} \mathrm{NMR}\left(\mathrm{CDCl}_{3}, 75 \mathrm{MHz}\right) \delta 158.7,146.2,142.4,131.1,128.8,127.38$, 127.37, 127.1, 122.6, 91.1, 27.5, 23.5. MS (m/z) $979\left(2 \mathrm{M}^{+}+\mathrm{Na}, 40\right), 501\left(\mathrm{M}^{+}+\mathrm{Na}, 20\right)$, 243 (100). Anal. Calcd for $\mathrm{C}_{32} \mathrm{H}_{34} \mathrm{~N}_{2} \mathrm{O}_{2}$ : C, 80.30; H, 7.16; N, 5.85. Found: C, 80.29; H, $7.26 ; \mathrm{N}, 5.85$.

Preparation of (7)

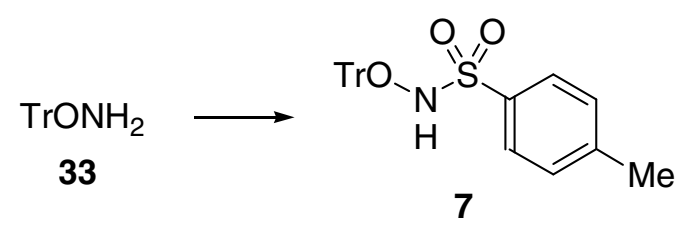

To a solution of 33 (1.91 g, $5.5 \mathrm{mmol}, 1.1$ equiv) in $\mathrm{CH}_{2} \mathrm{Cl}_{2}(6 \mathrm{~mL})$ was added pyridine $(3 \mathrm{~mL})$ and then 4-toluenesulfonyl chloride $(950 \mathrm{mg}, 5.0 \mathrm{mmol})$ at room temperature. The mixture was stirred at $\mathrm{rt}$ for $3 \mathrm{~h}$ and was poured into EtOAc/ $\mathrm{H}_{2} \mathrm{O}(100 \mathrm{~mL} / 100 \mathrm{~mL})$. The organic layer was washed with $0.5 \mathrm{~N} \mathrm{HCl}_{(\mathrm{aq})}(100 \mathrm{~mL}), \mathrm{H}_{2} \mathrm{O}(100 \mathrm{~mL})$, brine $(100 \mathrm{~mL})$, dried $\left(\mathrm{Na}_{2} \mathrm{SO}_{4}\right)$, and filtered. After removal of solvent, to the crude mixture was added $\mathrm{Et}_{2} \mathrm{O}(20 \mathrm{~mL})$ and then hexane $(60 \mathrm{~mL})$. The resulting solid was filtered and was washed with $\mathrm{Et}_{2} \mathrm{O} /$ hexane $(1 / 4,30 \mathrm{~mL})$ and then dried to give $2.18 \mathrm{~g}$ of $7(89 \%)$ as a white solid. ${ }^{1} \mathrm{H}$ NMR $\left(\mathrm{CDCl}_{3}, 300 \mathrm{MHz}\right) \delta 7.71(\mathrm{~d}, J=9.0 \mathrm{~Hz}, 2 \mathrm{H}), 7.33-7.23(\mathrm{~m}, 17 \mathrm{H}), 6.47$ (s, 1 $\mathrm{H}, \mathrm{NH}), 2.43(\mathrm{~s}, 3 \mathrm{H}) .{ }^{13} \mathrm{C} \mathrm{NMR}\left(\mathrm{d}_{6}\right.$-acetone, $\left.100 \mathrm{MHz}\right) \delta 145.2,143.5,136.2,130.3$, 129.6, 128.4, 93.3, 21.6. MS (m/z) $452\left(\mathrm{M}^{+}+\mathrm{Na}, 80\right), 243$ (100), 100 (25). Anal. Calcd for $\mathrm{C}_{26} \mathrm{H}_{23} \mathrm{NO}_{3} \mathrm{~S}$ : C, 72.70; H, 5.40; N, 3.26. Found: C, 72.48; H, 5.22; N, 3.16.

Preparation of $(\mathbf{8})$
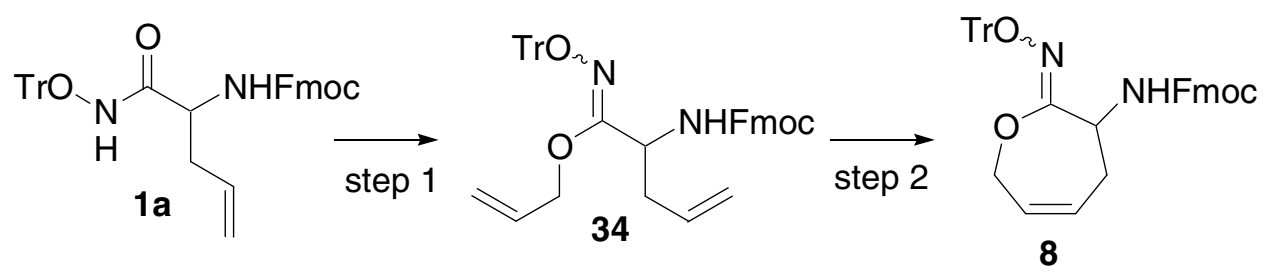

\section{Step 1:}


To a mixture of $1 \mathrm{a}(1.78 \mathrm{~g}, 3.0 \mathrm{mmol})$ and $\mathrm{K}_{2} \mathrm{CO}_{3}(621 \mathrm{mg}, 4.5 \mathrm{mmol}, 1.5$ equiv) was added acetone $(12 \mathrm{~mL})$ at room temperature. Then, allyl bromide $(1.3 \mathrm{~mL}, 15.0 \mathrm{mmol}$, 5.0 equiv) was added. The mixture was stirred at $\mathrm{rt}$ for $24 \mathrm{~h}$ and was poured into EtOAc/ $\mathrm{H}_{2} \mathrm{O}(100 \mathrm{~mL} / 100 \mathrm{~mL})$. The organic layer was washed with brine $(100 \mathrm{~mL})$, dried $\left(\mathrm{Na}_{2} \mathrm{SO}_{4}\right)$, and filtered. After removal of solvent, the product was purified by silica gel chromatography using EtOAc/hexane (1/19 to 1/3) as the eluent to give $1.25 \mathrm{~g}$ of $\mathbf{3 4}$ (66\%, one geometric isomer) as a sticky oil. (340 mg of $N$-alkylated product was also isolated.) ${ }^{1} \mathrm{H} \mathrm{NMR}\left(\mathrm{CDCl}_{3}, 300 \mathrm{MHz}\right) \delta 7.45(\mathrm{~d}, J=6.0 \mathrm{~Hz}, 2 \mathrm{H}), 7.57-7.23(\mathrm{~m}, 21 \mathrm{H})$, 6.01-5.88 (m, $1 \mathrm{H}), 5.49-5.37(\mathrm{~m}, 1 \mathrm{H}), 5.31(\mathrm{~d}, J=15.0 \mathrm{~Hz}, 1 \mathrm{H}), 5.22(\mathrm{dd}, J=12.0,3.0$ $\mathrm{Hz}, 1 \mathrm{H}), 5.02-4.84$ (m, 5 H), 4.31-4.22 (m, $2 \mathrm{H}), 4.13(\mathrm{t}, J=6.0 \mathrm{~Hz}, 1 \mathrm{H}), 2.41-2.17$ (m, $2 \mathrm{H}) .{ }^{13} \mathrm{C}$ NMR $\left(\mathrm{CDCl}_{3}, 100 \mathrm{MHz}\right) \delta 155.3,152.4,144.1,144.0,141.3,133.3,132.9$, 129.1, 127.7, 127.5, 127.1, 127.0, 125.1, 120.0, 118.4, 118.1, 91.6, 72.3, 66.8, 51.6, 47.2, 37.1. MS (m/z) $657\left(\mathrm{M}^{+}+\mathrm{Na}, 30\right), 635\left(\mathrm{M}^{+}+1,50\right), 453$ (100), 243 (40). Anal. Calcd for $\mathrm{C}_{42} \mathrm{H}_{38} \mathrm{~N}_{2} \mathrm{O}_{4}:$ C, 79.47; H, 6.03; N, 4.41. Found: C, 79.34; H, 6.09; N, 4.42.

\section{Step 2:}

In a three-necked flask was placed $34(3.81 \mathrm{~g}, 6.0 \mathrm{mmol})$. The air was removed and was refilled with $\mathrm{N}_{2}$ for three times. $\mathrm{CH}_{2} \mathrm{Cl}_{2}(240 \mathrm{~mL})$ and Grubbs II catalyst $(203 \mathrm{mg}, 0.24$ mmol, 0.04 equiv) were added sequentially. The mixture was stirred at room temperature for $3 \mathrm{~h}$. The mixture was then stirred for 30 min under air. The mixture was filtered through silica gel $(70 \mathrm{~g})$ and was eluted with $\mathrm{CH}_{2} \mathrm{Cl}_{2}(50 \mathrm{~mL})$ then EtOAc/hexane (7/13, $300 \mathrm{~mL}$ ). The EtOAc/hexane filtrate was collected and the solvent was removed. The crude mixture was purified by silica gel chromatography using EtOAc/hexane (1/9 to 1/4) as the eluent to give $3.34 \mathrm{~g}$ of $\mathbf{8}$ (92\%, one geometric isomer) as a brown solid. ${ }^{1} \mathrm{H}$ NMR $\left(\mathrm{CDCl}_{3}, 300 \mathrm{MHz}\right) \delta 7.77$ (d, $\left.J=9.0 \mathrm{~Hz}, 2 \mathrm{H}\right), 7.49(\mathrm{~d}, J=6.0 \mathrm{~Hz}, 2 \mathrm{H}), 7.42-7.16(\mathrm{~m}, 19$ H), 5.79 (br s, 2 H), 5.46 (d, $J=6.0 \mathrm{~Hz}, 1 \mathrm{H}, \mathrm{NH}), 4.91-4.86$ (m, $2 \mathrm{H}$ ), 4.53 (dd, $J=12.0$, $6.0 \mathrm{~Hz}, 1 \mathrm{H}), 4.32-4.19(\mathrm{~m}, 2 \mathrm{H}), 4.12(\mathrm{t}, J=6.0 \mathrm{~Hz}, 1 \mathrm{H}), 2.78$ (br d, $J=18.0 \mathrm{~Hz}, 1 \mathrm{H}$ ), 2.14 (br t $, J=15.0 \mathrm{~Hz}, 1 \mathrm{H}) .{ }^{13} \mathrm{C} \mathrm{NMR}\left(\mathrm{CDCl}_{3}, 75 \mathrm{MHz}\right) \delta 155.13,155.07,144.3$, 143.93, 143.87, 141.3, 130.4, 129.1, 127.7, 127.5, 127.1, 125.1, 125.0, 120.0, 90.7, 66.9, 65.0, 48.0, 47.2, 36.6. MS ( $\mathrm{m} / z) 629\left(\mathrm{M}^{+}+\mathrm{Na}, 60\right), 607\left(\mathrm{M}^{+}+1,100\right), 307(40), 243(25)$. 
Anal. Calcd for $\mathrm{C}_{40} \mathrm{H}_{34} \mathrm{~N}_{2} \mathrm{O}_{4}$ : C, 79.19; H, 5.65; N, 4.62. Found: C, 79.05; H, 5.81; N, 4.41. 


\section{Lewis Acid Promoted Detritylation}

General Procedure I: $\mathrm{MgBr}_{2}$ Promoted Deprotection of Trityl Group.

To a mixture of Trityl-protected substrate (1.0-2.0 mmol, 1.0equiv) and $\mathrm{MgBr}_{2}$ (5.0-10.0 mmol, 5.0-10.0 equiv) was added $\mathrm{CH}_{2} \mathrm{Cl}_{2}(10-20 \mathrm{~mL}, 0.1 \mathrm{M})$ at room temperature. The yellow suspension was stirred at $\mathrm{rt}$ and was poured into $\mathrm{EtOAc} / \mathrm{H}_{2} \mathrm{O}$ (1/1) after completion. The organic layer was washed with brine (50-100 mL), dried $\left(\mathrm{Na}_{2} \mathrm{SO}_{4}\right)$, and filtered. After removal of solvent, the product can be purified by silica gel chromatography using EtOAc/hexane as the eluent or precipitated from $\mathrm{Et}_{2} \mathrm{O} /$ hexane or acetone/hexane to give desired product.

General Procedure II: $\mathrm{BF}_{3} \cdot \mathrm{Et}_{2} \mathrm{O}$ Promoted Deprotection of Trityl Group.

To a mixture of Trityl-protected substrate (1.0-2.0 mmol, 1.0equiv) in $\mathrm{CH}_{2} \mathrm{Cl}_{2} / \mathrm{MeOH}$ (4.1 to $1 / 1,10-20 \mathrm{~mL}, 0.1 \mathrm{M}$ ) was added $\mathrm{BF}_{3} \cdot \mathrm{OEt}_{2}(2.0-4.0 \mathrm{mmol}, 2.0$ equiv) at room temperature. The mixture was stirred at $\mathrm{rt}$ and was poured into EtOAc/ $\mathrm{H}_{2} \mathrm{O}(1 / 1)$ after completion. The organic layer was washed with brine, dried $\left(\mathrm{Na}_{2} \mathrm{SO}_{4}\right)$, and filtered. After removal of solvent, the product can be purified by silica gel chromatography using EtOAc/hexane as the eluent or precipitated from $\mathrm{Et}_{2} \mathrm{O} /$ hexane or acetone/hexane to give pure product.

Preparation of (9a)

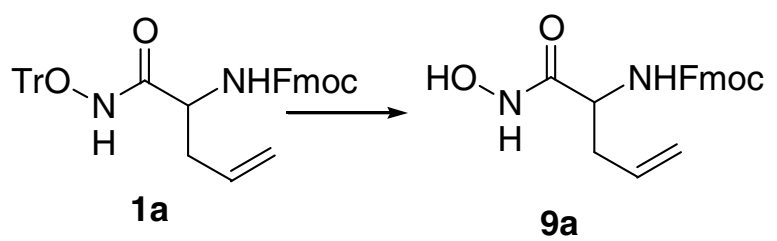

Method A: According to the General Procedure I, 1a (594 mg, $1.0 \mathrm{mmol}$ ), $\mathrm{MgBr}_{2}$ (921 $\mathrm{mg}, 5.0 \mathrm{mmol})$, and $\mathrm{CH}_{2} \mathrm{Cl}_{2}(10 \mathrm{~mL})$ were combined. The mixture was stirred at $\mathrm{rt}$ for 40 $\mathrm{min}$. The product was precipitated from acetone/hexane $(10 \mathrm{~mL} / 50 \mathrm{~mL})$ to give $303 \mathrm{mg}$ of $9 \mathbf{a}(86 \%)$ as a white solid. 
Method B: According to the General Procedure II, 1a (594 mg, $1.0 \mathrm{mmol}), \mathrm{BF}_{3} \cdot \mathrm{OEt}_{2}$ (0.25 mL, $2.0 \mathrm{mmol})$, and $\mathrm{CH}_{2} \mathrm{Cl}_{2} / \mathrm{MeOH}(5 \mathrm{~mL} / 5 \mathrm{~mL})$ were combined. The mixture was stirred at $\mathrm{rt}$ for $15 \mathrm{~min}$. The product was precipitated from $\mathrm{Et}_{2} \mathrm{O} / \mathrm{hexane}(10 \mathrm{~mL} / 50 \mathrm{~mL})$ to give $314 \mathrm{mg}$ of $\mathbf{9 a}(89 \%)$ as a white solid.

Method C: To a mixture of 1a $(594 \mathrm{mg}, 1.0 \mathrm{mmol})$ and Amberlyst ${ }^{\circledR} 15$ ionexchange resin $(1 \mathrm{~g})$ was added $\mathrm{CH}_{2} \mathrm{Cl}_{2} / \mathrm{MeOH}(5 \mathrm{~mL} / 5 \mathrm{~mL})$. The mixture was stirred at room temperature for $6 \mathrm{~h}$. The mixture was filtered through a short path of silica gel and was eluted with EtOAc $(50 \mathrm{~mL})$. The filtrate was concentrated and the product was precipitated from acetone/hexane $(10 \mathrm{~mL} / 50 \mathrm{~mL})$ to give $290 \mathrm{mg}$ of $9 \mathbf{a}(82 \%)$ as a white solid. ${ }^{1} \mathrm{H}$ NMR (d $\mathrm{d}_{6}$-DMSO, $\left.300 \mathrm{MHz}\right) \delta 10.64$ (s, $\left.1 \mathrm{H}\right), 8.84$ (s, $\left.1 \mathrm{H}\right), 7.89$ (d, J = $6.0 \mathrm{~Hz}$, $2 \mathrm{H}), 7.73(\mathrm{~d}, J=6.0 \mathrm{~Hz}, 2 \mathrm{H}), 7.56(\mathrm{~d}, J=9.0 \mathrm{~Hz}, 1 \mathrm{H}, \mathrm{NH}), 7.42$ (t, $J=6.0 \mathrm{~Hz}, 2 \mathrm{H})$, $7.33(\mathrm{t}, J=6.0 \mathrm{~Hz}, 2 \mathrm{H}), 5.78-5.64(\mathrm{~m}, 1 \mathrm{H}), 5.13-5.02(\mathrm{~m}, 2 \mathrm{H}), 4.27-4.20$ (m, $3 \mathrm{H}), 3.94$ $(\mathrm{dd}, J=15.0,6.0 \mathrm{~Hz}, 1 \mathrm{H}), 2.34-2.28(\mathrm{~m}, 2 \mathrm{H}) .{ }^{13} \mathrm{C} \mathrm{NMR}\left(\mathrm{d}_{6}\right.$-DMSO, $\left.75 \mathrm{MHz}\right) \delta 167.9$, 155.7, (143.85, 143.75), 140.7, 134.1, 127.6, 127.0, 125.3, 120.1, 117.6, 65.7, 52.1, 46.6, 36.2. MS $(m / z) 375\left(\mathrm{M}^{+}+\mathrm{Na}, 100\right), 353\left(\mathrm{M}^{+}+1,10\right)$. Anal. Calcd for $\mathrm{C}_{20} \mathrm{H}_{20} \mathrm{~N}_{2} \mathrm{O}_{4}: \mathrm{C}$, 68.17; H, 5.72; N, 7.95. Found: C, 67.77; H, 5.57; N, 7.87.

Preparation of $(\mathbf{9 b})$

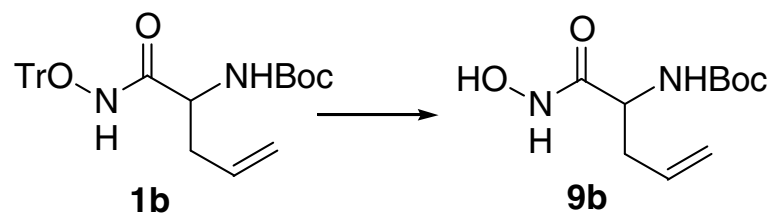

Method A: According to the General Procedure I, 1 b (944 mg, $2.0 \mathrm{mmol}), \mathrm{MgBr}_{2}$ (1.84 $\mathrm{g}, 10.0 \mathrm{mmol})$, and $\mathrm{CH}_{2} \mathrm{Cl}_{2}(20 \mathrm{~mL})$ were combined. The mixture was stirred at $\mathrm{rt}$ for 25 min. The product was precipitated from $\mathrm{Et}_{2} \mathrm{O} /$ hexane $(15 \mathrm{~mL} / 85 \mathrm{~mL})$ to give $323 \mathrm{mg}$ of 9b (70\%) as a white solid.

Method B: According to the General Procedure II, $\mathbf{1 b}(472 \mathrm{mg}, 1.0 \mathrm{mmol}), \mathrm{BF}_{3} \cdot \mathrm{OEt}_{2}$ (0.25 mL, $2.0 \mathrm{mmol})$, and $\mathrm{CH}_{2} \mathrm{Cl}_{2} / \mathrm{MeOH}(8 \mathrm{~mL} / 2 \mathrm{~mL})$ were combined. The mixture was stirred at $\mathrm{rt}$ for $10 \mathrm{~min}$. The product was precipitated from $\mathrm{Et}_{2} \mathrm{O} / \mathrm{hexane}(15 \mathrm{~mL} / 85 \mathrm{~mL})$ to give $175 \mathrm{mg}$ of $\mathbf{9 b}(76 \%)$ as a white solid. ${ }^{1} \mathrm{H}$ NMR (d $\mathrm{d}_{6}$-acetone, $\left.400 \mathrm{MHz}\right) \delta 10.17(\mathrm{~s}, 1$ 
H), 8.09 (br s, $1 \mathrm{H}), 5.99$ (br s, $1 \mathrm{H}, \mathrm{NH}), 5.84-5.74$ (m, $1 \mathrm{H}), 5.13$ (d, J = $17.2 \mathrm{~Hz}, 1 \mathrm{H})$, $5.06(\mathrm{~d}, J=10.4 \mathrm{~Hz}, 1 \mathrm{H}), 4.09-4.04(\mathrm{~m}, 1 \mathrm{H}), 2.52-2.39(\mathrm{~m}, 2 \mathrm{H}), 1.41(\mathrm{~s}, 9 \mathrm{H}) .{ }^{13} \mathrm{C}$ NMR $\left(\mathrm{d}_{6}\right.$-acetone, $\left.100 \mathrm{MHz}\right) \delta 167.8,154.4,133.0,116.4,77.6,51.1,35.7,26.7 . \mathrm{MS}$ $(m / z) 253\left(\mathrm{M}^{+}+\mathrm{Na}, 100\right), 175(90), 131$ (15), 100 (15). Anal. Calcd for $\mathrm{C}_{10} \mathrm{H}_{18} \mathrm{~N}_{2} \mathrm{O}_{4}$ : C, 52.16; H, 7.88; N, 12.17. Found: C, 52.15; H, 7.94; N, 11.95.

Preparation of $(\mathbf{9 c})$<smiles>C=CCC(NC(=O)OCc1ccccc1)C(=O)NOC(=O)C(CC=C)NC(=O)OCC</smiles>

According to the General Procedure I, $1 \mathrm{c}(1.01 \mathrm{~g}, 2.0 \mathrm{mmol}), \mathrm{MgBr}_{2}(1.84 \mathrm{~g}, 10.0 \mathrm{mmol})$, and $\mathrm{CH}_{2} \mathrm{Cl}_{2}(20 \mathrm{~mL})$ were combined. The mixture was stirred at $\mathrm{rt}$ for $1 \mathrm{~h}$. The product was precipitated from acetone/hexane $(15 \mathrm{~mL} / 75 \mathrm{~mL})$ to give $428 \mathrm{mg}$ of $9 \mathrm{c}(81 \%)$ as a white solid. ${ }^{1} \mathrm{H}$ NMR (d $\mathrm{d}_{6}$-DMSO, $\left.300 \mathrm{MHz}\right) \delta 10.63$ (s, $\left.1 \mathrm{H}\right), 8.84$ (s, $\left.1 \mathrm{H}\right)$, 7.45-7.19 (m, $6 \mathrm{H}), 5.75-5.64(\mathrm{~m}, 1 \mathrm{H}), 5.11-5.05(\mathrm{~m}, 2 \mathrm{H}), 5.01(\mathrm{~s}, 2 \mathrm{H}), 3.93(\mathrm{dd}, J=12.0,6.0 \mathrm{~Hz}, 1$ $\mathrm{H}), 2.37-2.25(\mathrm{~m}, 2 \mathrm{H}) .{ }^{13} \mathrm{C} \mathrm{NMR}\left(\mathrm{d}_{6}-\mathrm{DMSO}, 75 \mathrm{MHz}\right) \delta 167.9,155.7,137.0,134.1$, 128.3, 127.7, 127.6, 117.6, 65.3, 52.1, 36.2. MS $(\mathrm{m} / z) 287\left(\mathrm{M}^{+}+\mathrm{Na}, 35\right), 265\left(\mathrm{M}^{+}+1\right.$, 100), 221 (10), 100 (10). HRMS Calcd for $\mathrm{C}_{13} \mathrm{H}_{17} \mathrm{~N}_{2} \mathrm{O}_{4}\left(\mathrm{M}^{+}+\mathrm{H}\right)$ : 265.1188. Found: 265.1194 .

Preparation of (10)

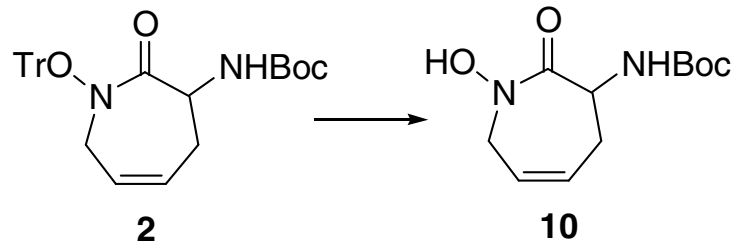

Method A: According to the General Procedure I, 2 (484 mg, $1.0 \mathrm{mmol}), \mathrm{MgBr}_{2}$ (921 $\mathrm{mg}, 5.0 \mathrm{mmol})$, and $\mathrm{CH}_{2} \mathrm{Cl}_{2}(10 \mathrm{~mL})$ were combined. The mixture was stirred at $\mathrm{rt}$ for 10 min. The product was purified by silica gel chromatography using EtOAc/hexane (3/7 to $7 / 3)$ as the eluent to give $160 \mathrm{mg}$ of $\mathbf{1 0}(66 \%)$ as a white solid. 
Method B: According to the General Procedure II, 2 (484 mg, $1.0 \mathrm{mmol}), \mathrm{BF}_{3} \cdot \mathrm{OEt}_{2}(0.25$ $\mathrm{mL}, 2.0 \mathrm{mmol})$, and $\mathrm{CH}_{2} \mathrm{Cl}_{2} / \mathrm{MeOH}(8 \mathrm{~mL} / 2 \mathrm{~mL})$ were combined. The mixture was stirred at rt for $10 \mathrm{~min}$. The product was purified by silica gel chromatography using EtOAc/hexane (3/7 to 7/3) as the eluent to give $179 \mathrm{mg}$ of $\mathbf{1 0}(74 \%)$ as a white solid. ${ }^{1} \mathrm{H}$ NMR $\left(\mathrm{CDCl}_{3}, 300 \mathrm{MHz}\right) \delta 8.12(\mathrm{~s}, 1 \mathrm{H}), 5.82-5.69(\mathrm{~m}, 2 \mathrm{H}), 5.65(\mathrm{~d}, J=6.0 \mathrm{~Hz}, 1 \mathrm{H}$, $\mathrm{NH}), 4.77-4.69$ (m, $1 \mathrm{H}), 5.57$ (dd, $J=18.0,2.1 \mathrm{~Hz}, 1 \mathrm{H}), 4.02(\mathrm{dd}, J=18.0,6.0 \mathrm{~Hz}, 1$ H), $2.63(\mathrm{dd}, J=18.0,3.9 \mathrm{~Hz}, 1 \mathrm{H}), 2.26(\mathrm{td}, J=16.0,1.8 \mathrm{~Hz}, 1 \mathrm{H}), 1.45(\mathrm{~s}, 9 \mathrm{H}) .{ }^{13} \mathrm{C}$ NMR $\left(\mathrm{CDCl}_{3}, 75 \mathrm{MHz}\right) \delta 167.5,155.0,129.3,122.4,80.0,49.2,48.8,32.3$, 28.3. MS $(m / z) 507\left(2 \mathrm{M}^{+}+\mathrm{Na}, 100\right), 265\left(\mathrm{M}^{+}+\mathrm{Na}, 40\right), 187$ (40). Anal. Calcd for $\mathrm{C}_{11} \mathrm{H}_{18} \mathrm{~N}_{2} \mathrm{O}_{4}: \mathrm{C}$, 54.53; H, 7.49; N, 11.56. Found: C, 54.53; H, 7.69; N, 11.41.

Preparation of (11)

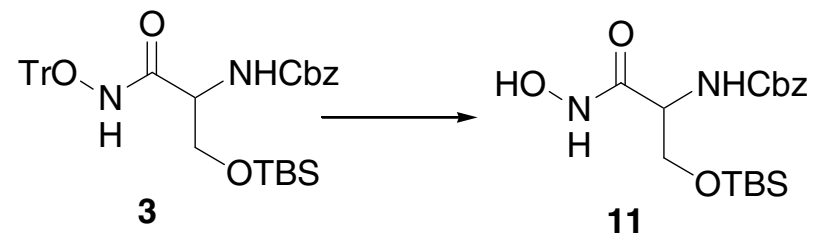

According to the General Procedure I, 3 (610 mg, $1.0 \mathrm{mmol}), \mathrm{MgBr}_{2}(921 \mathrm{mg}, 5.0$ $\mathrm{mmol})$, and $\mathrm{CH}_{2} \mathrm{Cl}_{2}(10 \mathrm{~mL})$ were combined. The product was purified by silica gel chromatography using EtOAc/hexane (3/7 to 7/3) as the eluent to give $291 \mathrm{mg}$ of 11 (79\%) as a sticky oil. ${ }^{1} \mathrm{H}$ NMR (d 6 -acetone, $\left.300 \mathrm{MHz}\right) \delta 10.18(\mathrm{~s}, 1 \mathrm{H}), 8.06(\mathrm{~s}, 1 \mathrm{H})$, 7.32-7.23 (m, 5 H), 6.23 (d, J=6.4 Hz, 1 H, NH), 5.01 (s, 2 H), 4.17-4.15 (m, 1 H), 3.83$3.77(\mathrm{~m}, 2 \mathrm{H}), 0.82(\mathrm{~s}, 9 \mathrm{H}), 0.00(\mathrm{~s}, 6 \mathrm{H}) .{ }^{13} \mathrm{C}$ NMR $\left(\mathrm{d}_{6}\right.$-acetone, $\left.100 \mathrm{MHz}\right) \delta 165.8$, 154.6, 135.9, 127.1, 126.6, 64.8, 62.0, 53.7, 24.1, 16.7, -7.45, -7.47. MS (m/z) 391 $\left(\mathrm{M}^{+}+\mathrm{Na}, 100\right), 369\left(\mathrm{M}^{+}+1,80\right), 325$ (5), 100 (10). Anal. Calcd for $\mathrm{C}_{17} \mathrm{H}_{28} \mathrm{~N}_{2} \mathrm{O}_{5} \mathrm{Si}: \mathrm{C}$, 55.41; H, 7.66; N, 7.60. Found: C, 55.20; H, 7.86; N, 7.53.

Preparation of (12)

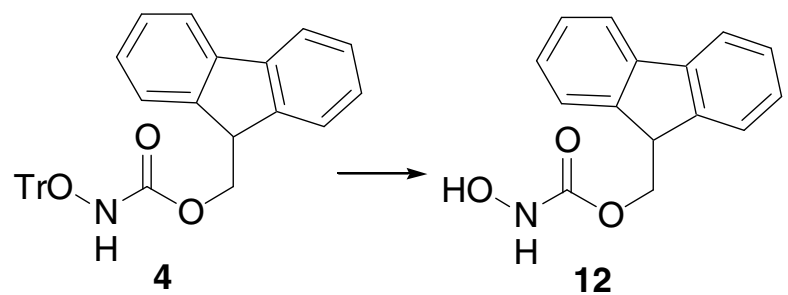


Method A: According to the General Procedure I, 4 (497 mg, $1.0 \mathrm{mmol}), \mathrm{MgBr}_{2}(921$ $\mathrm{mg}, 5.0 \mathrm{mmol})$, and $\mathrm{CH}_{2} \mathrm{Cl}_{2}(10 \mathrm{~mL})$ were combined. The mixture was stirred at $\mathrm{rt}$ for 3 h. The product was precipitated from $\mathrm{CH}_{2} \mathrm{Cl}_{2} /$ hexane $(10 \mathrm{~mL} / 30 \mathrm{~mL})$ to give $227 \mathrm{mg}$ of $12(89 \%)$ as a white solid.

Method B: According to the General Procedure II, 4 (994 mg, $2.0 \mathrm{mmol}), \mathrm{BF}_{3} \cdot \mathrm{OEt}_{2}(0.50$ $\mathrm{mL}, 4.0 \mathrm{mmol})$, and $\mathrm{CH}_{2} \mathrm{Cl}_{2} / \mathrm{MeOH}(16 \mathrm{~mL} / 4 \mathrm{~mL})$ were combined. The mixture was stirred at $\mathrm{rt}$ for $45 \mathrm{~min}$. The product was precipitated from $\mathrm{CH}_{2} \mathrm{Cl}_{2} /$ hexane $(10 \mathrm{~mL} / 30$ $\mathrm{mL})$ to give $474 \mathrm{mg}$ of $12(93 \%)$ as a white solid. ${ }^{1} \mathrm{H}$ NMR (d $\mathrm{d}_{6}$-DMSO, $\left.300 \mathrm{MHz}\right) \delta 9.75$ $(\mathrm{s}, 1 \mathrm{H}), 8.77(\mathrm{~s}, 1 \mathrm{H}), 7.90(\mathrm{~d}, J=9.0 \mathrm{~Hz}, 2 \mathrm{H}), 7.69(\mathrm{~d}, J=9.0 \mathrm{~Hz}, 2 \mathrm{H}), 7.42(\mathrm{t}, J=9.0$ $\mathrm{Hz}, 2 \mathrm{H}), 7.33(\mathrm{t}, J=9.0 \mathrm{~Hz}, 2 \mathrm{H}), 4.33(\mathrm{~d}, J=6.0 \mathrm{~Hz}, 2 \mathrm{H}), 4.23(\mathrm{t}, J=6.0 \mathrm{~Hz}, 1 \mathrm{H}) .{ }^{13} \mathrm{C}$ NMR (d ${ }_{6}$-DMSO, 75 MHz) $\delta$ 157.6, 143.7, 140.7, 127.6, 127.1, 125.2, 120.1, 65.6, 46.6. MS $(m / z) 278\left(\mathrm{M}^{+}+\mathrm{Na}, 100\right), 179$ (10). Anal. Calcd for $\mathrm{C}_{15} \mathrm{H}_{13} \mathrm{NO}_{3}: \mathrm{C}, 70.58 ; \mathrm{H}, 5.13 ; \mathrm{N}$, 5.49. Found: C, 70.16; H, 4.90; N, 5.39.

Preparation of (13)

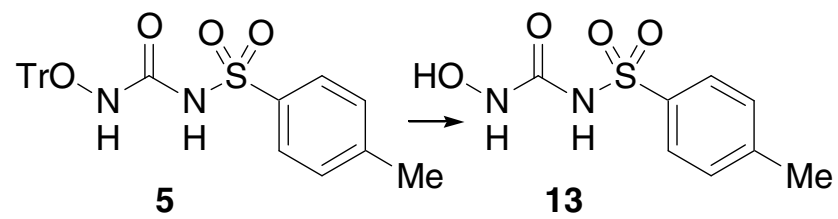

Method A: According to the General Procedure I, 5 (472 mg, $1.0 \mathrm{mmol}), \mathrm{MgBr}_{2}(921$ $\mathrm{mg}, 5.0 \mathrm{mmol})$, and $\mathrm{CH}_{2} \mathrm{Cl}_{2}(10 \mathrm{~mL})$ were combined. The mixture was stirred at $\mathrm{rt}$ for 45 min. The product was precipitated from $\mathrm{Et}_{2} \mathrm{O} /$ hexane $(15 \mathrm{~mL} / 60 \mathrm{~mL})$ to give $196 \mathrm{mg}$ of $13(85 \%)$ as a white solid.

Method B: According to the General Procedure II, 5 (472 mg, $1.0 \mathrm{mmol}), \mathrm{BF}_{3} \cdot \mathrm{OEt}_{2}(0.25$ $\mathrm{mL}, 2.0 \mathrm{mmol})$, and $\mathrm{CH}_{2} \mathrm{Cl}_{2} / \mathrm{MeOH}(5 \mathrm{~mL} / 5 \mathrm{~mL})$ were combined. The mixture was stirred at $\mathrm{rt}$ for $45 \mathrm{~min}$. The product was precipitated from $\mathrm{Et}_{2} \mathrm{O} / \mathrm{hexane}(15 \mathrm{~mL} / 60 \mathrm{~mL})$ to give $191 \mathrm{mg}$ of $13(83 \%)$ as a white solid. ${ }^{1} \mathrm{H}$ NMR $\left(\mathrm{d}_{6}-\mathrm{DMSO}, 300 \mathrm{MHz}\right) \delta 10.68(\mathrm{~s}, 1$ H), $9.32(\mathrm{~s}, 1 \mathrm{H}), 8.91(\mathrm{~s}, 1 \mathrm{H}), 7.80$ (d, J = 9.0 Hz, 2 H), 7.39 (d, J = 9.0 Hz, 2 H), 2.39 (s, $3 \mathrm{H}) .{ }^{13} \mathrm{C}$ NMR $\left(\mathrm{d}_{6}\right.$-DMSO, $\left.100 \mathrm{MHz}\right) \delta 154.0,143.4,137.6$, (129.3, 129.2), (127.4, 
127.3), (21.01, 20.99). MS ( $\mathrm{m} / \mathrm{z}) 253\left(\mathrm{M}^{+}+\mathrm{Na}, 100\right), 231\left(\mathrm{M}^{+}+1,40\right), 100$ (20). Anal. Calcd for $\mathrm{C}_{8} \mathrm{H}_{10} \mathrm{~N}_{2} \mathrm{O}_{4} \mathrm{~S}$ : C, 41.73; H, 4.38; N, 12.17. Found: C, 42.20; H, 4.38; N, 11.81.

Preparation of (14)

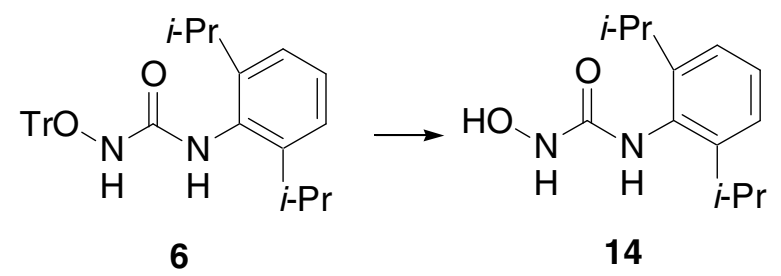

Method A: According to the General Procedure I, 6 (478 mg, $1.0 \mathrm{mmol}$ ), $\mathrm{MgBr}_{2}$ (921 $\mathrm{mg}$, $5.0 \mathrm{mmol})$, and $\mathrm{CH}_{2} \mathrm{Cl}_{2}(10 \mathrm{~mL})$ were combined. The mixture was stirred at $\mathrm{rt}$ for 6 h. The product was precipitated from $\mathrm{Et}_{2} \mathrm{O} /$ hexane $(15 \mathrm{~mL} / 85 \mathrm{~mL})$ to give $217 \mathrm{mg}$ of $\mathbf{1 4}$ $(92 \%)$ as a white solid.

Method B: According to the General Procedure II, 6 (478 mg, $1.0 \mathrm{mmol}), \mathrm{BF}_{3} \cdot \mathrm{OEt}_{2}(0.25$ $\mathrm{mL}, 2.0 \mathrm{mmol})$, and $\mathrm{CH}_{2} \mathrm{Cl}_{2} / \mathrm{MeOH}(8 \mathrm{~mL} / 2 \mathrm{~mL})$ were combined. The mixture was stirred at $\mathrm{rt}$ for $8 \mathrm{~h}$. The product was precipitated from $\mathrm{Et}_{2} \mathrm{O} / \mathrm{h}$ exane $(15 \mathrm{~mL} / 85 \mathrm{~mL})$ to give $201 \mathrm{mg}$ of $14(85 \%)$ as a white solid. ${ }^{1} \mathrm{H}$ NMR (d6-DMSO, $\left.300 \mathrm{MHz}\right) \delta 8.84(\mathrm{~s}, 1$ H), 8.54 (s, $1 \mathrm{H}), 8.09$ (s, $1 \mathrm{H}), 7.22(\mathrm{t}, J=7.5 \mathrm{~Hz}, 1 \mathrm{H}), 7.12(\mathrm{~d}, J=7.5 \mathrm{~Hz}, 2 \mathrm{H}), 3.14$ (sept, $J=6.0 \mathrm{~Hz}, 2 \mathrm{H}), 1.12(\mathrm{~d}, J=6.0 \mathrm{~Hz}, 12 \mathrm{H}) .{ }^{13} \mathrm{C}$ NMR $\left(\mathrm{d}_{6}\right.$-DMSO, $\left.100 \mathrm{MHz}\right) \delta$ 160.7, 146.7, 132.7, 127.1, 122.6, (27.79, 27.77), (23.8, 23.5). MS ( $\mathrm{m} / \mathrm{z}) 259\left(\mathrm{M}^{+}+\mathrm{Na}\right.$, 20), $237\left(\mathrm{M}^{+}+1,20\right)$. Anal. Calcd for $\mathrm{C}_{13} \mathrm{H}_{20} \mathrm{~N}_{2} \mathrm{O}_{2}$ : C, 66.07; H, 8.53; $\mathrm{N}, 11.85$. Found: $\mathrm{C}$, $66.08 ; \mathrm{H}, 8.63 ; \mathrm{N}, 11.60$.

Preparation of (15)

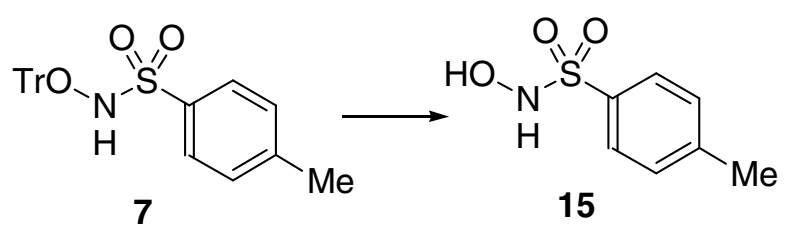

Method A: According to the similar procedure of General Procedure I, 7 (429 mg, 1.0 $\mathrm{mmol}), \mathrm{ZnBr}_{2}(1.125 \mathrm{~g}, 5.0 \mathrm{mmol})$, and $\mathrm{CH}_{2} \mathrm{Cl}_{2} / \mathrm{MeOH}(5 \mathrm{~mL} / 5 \mathrm{~mL})$ were combined. The mixture was stirred at $\mathrm{rt}$ for $36 \mathrm{~h}$. The product was purified by silica gel 
chromatography using EtOAc/hexane (3/7 to 7/3) as the eluent to give $118 \mathrm{mg}$ of 15 $(63 \%)$ as a white solid.

Method B: According to the General Procedure II, 7 (858 mg, $2.0 \mathrm{mmol}), \mathrm{BF}_{3} \cdot \mathrm{OEt}_{2}(0.5$ $\mathrm{mL}, 4.0 \mathrm{mmol})$, and $\mathrm{CH}_{2} \mathrm{Cl}_{2} / \mathrm{MeOH}(10 \mathrm{~mL} / 10 \mathrm{~mL})$ were combined. The mixture was stirred at $\mathrm{rt}$ for $4 \mathrm{~h}$. The product was purified by silica gel chromatography using EtOAc/hexane (3/7 to 7/3) as the eluent to give $299 \mathrm{mg}$ of $\mathbf{1 5}(80 \%)$ as a white solid. ${ }^{1} \mathrm{H}$ NMR (d $6_{6}$ DMSO, $\left.300 \mathrm{MHz}\right) \delta 9.53(\mathrm{~d}, J=3.0 \mathrm{~Hz}, 1 \mathrm{H}), 9.47$ (d, $\left.J=3.0 \mathrm{~Hz}, 1 \mathrm{H}\right), 7.72$ $(\mathrm{d}, J=9.0 \mathrm{~Hz}, 2 \mathrm{H}), 7.42(\mathrm{~d}, J=9.0 \mathrm{~Hz}, 2 \mathrm{H}), 2.40(\mathrm{~s}, 3 \mathrm{H}) . \mathrm{MS}(\mathrm{m} / \mathrm{z}) 210\left(\mathrm{M}^{+}+\mathrm{Na}, 15\right)$, $187\left(\mathrm{M}^{+}+1,100\right)$.

Preparation of (16)

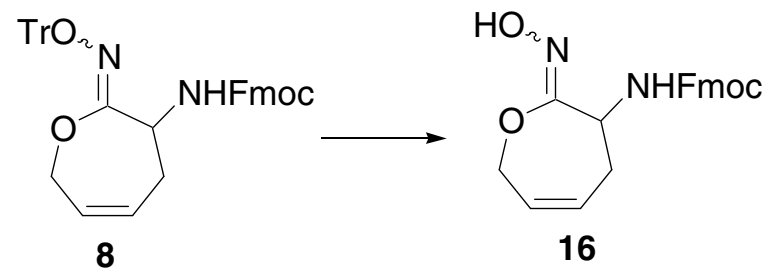

To a mixture of 8 (606 mg, $1.0 \mathrm{mmol})$ and $\mathrm{ZnBr}_{2}(2.25 \mathrm{~g}, 10 \mathrm{mmol}, 10.0$ equiv) was added $\mathrm{CH}_{2} \mathrm{Cl}_{2}(10 \mathrm{~mL})$ at room temperature. The yellow suspension was stirred at $\mathrm{rt}$ for $10 \mathrm{~min}$ and was poured into $\mathrm{EtOAc} / \mathrm{H}_{2} \mathrm{O}(50 \mathrm{~mL} / 50 \mathrm{~mL})$. The organic layer was washed with brine $(50 \mathrm{~mL})$, dried $\left(\mathrm{Na}_{2} \mathrm{SO}_{4}\right)$, and filtered. After removal of solvent, the product was purified by silica gel chromatography using EtOAc/hexane (1/4 to 3/2) as the eluent to give $298 \mathrm{mg}$ of $\mathbf{1 6}\left(82 \%\right.$, one geometric isomer) as a white solid. ${ }^{1} \mathrm{H} \mathrm{NMR}\left(\mathrm{CDCl}_{3}, 300\right.$ MHz) $\delta 7.76(\mathrm{~d}, J=7.5 \mathrm{~Hz}, 2 \mathrm{H}), 7.59(\mathrm{~d}, J=6.6 \mathrm{~Hz}, 2 \mathrm{H}), 7.41(\mathrm{t}, J=7.2 \mathrm{~Hz}, 2 \mathrm{H}), 7.31$ (t, $J=7.8 \mathrm{~Hz}, 2 \mathrm{H}), 6.52(\mathrm{~s}, 1 \mathrm{H}), 5.87-5.79(\mathrm{~m}, 3 \mathrm{H}), 5.08-5.01(\mathrm{~m}, 1 \mathrm{H}), 4.92(\mathrm{~d}, J=$ $15.9 \mathrm{~Hz}, 1 \mathrm{H}), 4.55(\mathrm{dd}, J=15.3,5.7 \mathrm{~Hz}, 1 \mathrm{H}), 4.45-4.38(\mathrm{~m}, 2 \mathrm{H}), 4.22(\mathrm{t}, J=7.2 \mathrm{~Hz}, 1$ H), 2.86 (br d, $J=17.7 \mathrm{~Hz}, 1 \mathrm{H}), 2.39$ (br t, $J=15.0 \mathrm{~Hz}, 1 \mathrm{H}) .{ }^{13} \mathrm{C}$ NMR (d 6 -DMSO, 75 MHz) $\delta 155.0,143.8,143.7,140.6,129.6,127.5,127.0,125.6,125.2,120.0,65.6,63.4$, 47.5, 46.6, 34.9. MS (m/z) $387\left(\mathrm{M}^{+}+\mathrm{Na}, 45\right), 365\left(\mathrm{M}^{+}+1,100\right)$. HRMS Calcd for $\mathrm{C}_{21} \mathrm{H}_{21} \mathrm{~N}_{2} \mathrm{O}_{4}\left(\mathrm{M}^{+}+\mathrm{H}\right)$ : 365.1501. Found: 365.1502. 


\section{Synthesis of (-)-Cobactin T}

Preparation of (27).

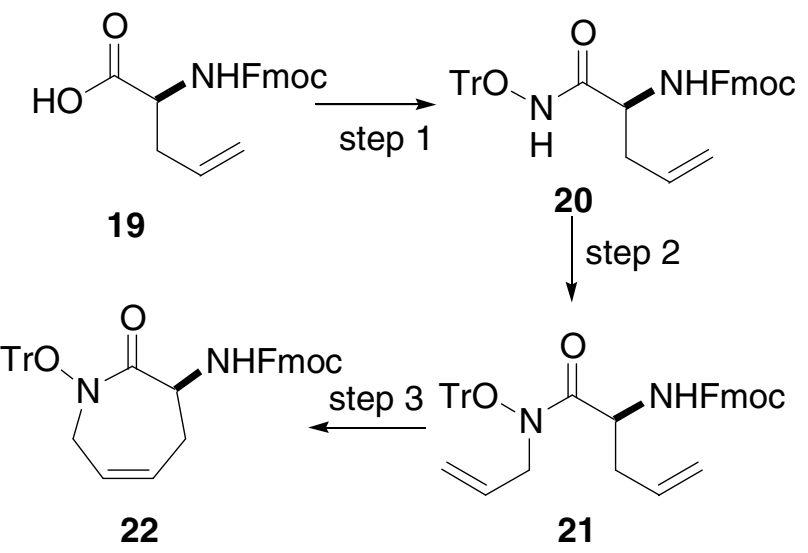

\section{Step 1:}

To a mixture of (L)- $N$-Fmoc-allylglycine $19(10.11 \mathrm{~g}, 30 \mathrm{mmol})$, EDC (8.59 g, $45 \mathrm{mmol}$, 1.5 equiv), $\mathrm{HOBt}\left(4.45 \mathrm{~g}, 33 \mathrm{mmol}, 1.1\right.$ equiv) was added $\mathrm{CH}_{2} \mathrm{Cl}_{2}(150 \mathrm{~mL}), \mathrm{N}$ methylmorpholine ( $8.57 \mathrm{~mL}, 78 \mathrm{mmol}, 2.6$ equiv), and then $O$-trityl hydroxylamine ( 6.88 $\mathrm{g}, 25 \mathrm{mmol}, 1.25$ equiv) sequentially at room temperature. The mixture was stirred at $\mathrm{rt}$ for $2 \mathrm{~h}$ and was then poured into $\mathrm{CHCl}_{3} / \mathrm{H}_{2} \mathrm{O}(100 \mathrm{~mL} / 200 \mathrm{~mL})$. The organic layer was separated and was washed with $\mathrm{H}_{2} \mathrm{O}(200 \mathrm{~mL})$, brine $(200 \mathrm{~mL})$, dried $\left(\mathrm{Na}_{2} \mathrm{SO}_{4}\right)$, and then filtered. After removal of solvent, $\mathrm{Et}_{2} \mathrm{O}(300 \mathrm{~mL})$ was added to the crude product. The white solid was filtered and was washed with $\mathrm{Et}_{2} \mathrm{O}(150 \mathrm{~mL})$. The solid was dried to give $15.86 \mathrm{~g}$ of 20 (89\%) as a white solid. ${ }^{1} \mathrm{H}$ NMR ( $\mathrm{d}_{6}$-DMSO, $\left.300 \mathrm{MHz}\right) \delta 10.54(\mathrm{~s}, 1 \mathrm{H})$, $7.89(\mathrm{~d}, J=6.0 \mathrm{~Hz}, 2 \mathrm{H}), 7.71(\mathrm{dd}, J=9.0,3.0 \mathrm{~Hz}, 2 \mathrm{H}), 7.42(\mathrm{t}, J=9.0 \mathrm{~Hz}, 2 \mathrm{H}), 7.35$ $7.24(\mathrm{~m}, 17 \mathrm{H}), 5.50-5.43(\mathrm{~m}, 1 \mathrm{H}), 4.98-4.91(\mathrm{~m}, 2 \mathrm{H}), 4.25-4.18(\mathrm{~m}, 3 \mathrm{H}), 3.94(\mathrm{~m}, 1$ $\mathrm{H}), 1.94-1.87$ (m, $2 \mathrm{H}) .{ }^{13} \mathrm{C}$ NMR (d 6 -DMSO, $\left.75 \mathrm{MHz}\right) \delta 169.1,155.6,(143.82,143.77)$, 142.2, 140.7, 134.1, 128.9, 127.6, 127.5, 127.4, 127.0, (125.35, 125.28), 120.1, 117.3, 92.0, 65.6, 51.6, 46.6, 35.8. MS (m/z) $617\left(\mathrm{M}^{+}+\mathrm{Na}, 15\right), 243$ (100), 179 (80),. Anal. Calcd for $\mathrm{C}_{39} \mathrm{H}_{34} \mathrm{~N}_{2} \mathrm{O}_{4}: \mathrm{C}, 78.77 ; \mathrm{H}, 5.76 ; \mathrm{N}, 4.71$. Found: C, 78.51; H, 5.66; N, 4.76.

\section{Step 2:}

In a three-necked flask was placed $20(14.85 \mathrm{~g}, 25 \mathrm{mmol})$. The air was removed and was refilled with $\mathrm{N}_{2}$ for three times. Then, dried $\mathrm{MeCN}(100 \mathrm{~mL})$, allyl methyl carbonate 
(5.65 mL, $50 \mathrm{mmol}, 2$ equiv), and $\mathrm{Pd}\left(\mathrm{PPh}_{3}\right)_{4}(578 \mathrm{mg}, 0.5 \mathrm{mmol}, 0.02$ equiv) were added sequentially at room temperature under $\mathrm{N}_{2}$. The mixture was stirred at $\mathrm{rt}$ for $45 \mathrm{~min}$ and was then poured into a mixture of EtOAc $(300 \mathrm{~mL})$ and brine $(300 \mathrm{~mL})$. The organic layer was separated, dried $\left(\mathrm{Na}_{2} \mathrm{SO}_{4}\right)$, and filtered. After removal of solvent, the crude mixture was purified by silica gel chromatography using EtOAc/hexane (1/9 to 1/4) as the eluent to give $13.63 \mathrm{~g}$ of $N$-allyl intermediate $21(86 \%)$ as a colorless oil. $[\alpha]_{\mathrm{D}}{ }^{20}$ : $-53.9^{\circ}\left(\mathrm{c}=1.5, \mathrm{CHCl}_{3}\right) .{ }^{1} \mathrm{H} \mathrm{NMR}\left(\mathrm{CDCl}_{3}, 300 \mathrm{MHz}\right) \delta 7.76(\mathrm{~d}, J=9.0 \mathrm{~Hz}, 2 \mathrm{H}), 7.56(\mathrm{~d}$, $J=9.0 \mathrm{~Hz}, 2 \mathrm{H}), 7.53$ (t, $J=9.0 \mathrm{~Hz}, 2 \mathrm{H}), 7.43-7.22(\mathrm{~m}, 18 \mathrm{H}), 5.82-5.71(\mathrm{~m}, 2 \mathrm{H}), 5.26-$ 5.09 (m, $4 \mathrm{H}), 4.55-4.40$ (m, $2 \mathrm{H}), 4.32-4.16$ (m, $3 \mathrm{H}), 3.59-3.54$ (m, $1 \mathrm{H}), 2.55-2.30$ (m, $2 \mathrm{H}) .{ }^{13} \mathrm{C} \mathrm{NMR}\left(\mathrm{CDCl}_{3}, 75 \mathrm{MHz}\right) \delta 173.5,154.7,(144.1,143.9), 141.7,141.3,132.8$, 131.9, 129.6, 128.2, 127.9, 127.7, 127.0, 125.3, 120.0, 118.6, 118.3, 95.1, 66.7, 50.9, 50.2, 47.2, 37.1. Anal. Calcd for $\mathrm{C}_{42} \mathrm{H}_{38} \mathrm{~N}_{2} \mathrm{O}_{4}$ : C, 79.47; H, 6.03; N, 4.41. Found: C, $79.22 ; \mathrm{H}, 6.09 ; \mathrm{N}, 4.42$.

\section{Step 3:}

In a three-necked flask was placed the $N$-allyl intermediate $21(6.34 \mathrm{~g}, 10.0 \mathrm{mmol})$. The air was removed and was refilled with $\mathrm{N}_{2}$ for three times. $\mathrm{CH}_{2} \mathrm{Cl}_{2}(400 \mathrm{~mL})$ and Grubbs II catalyst ( $425 \mathrm{mg}, 0.5 \mathrm{mmol}, 0.05$ equiv) were added sequentially. The mixture was stirred at $40{ }^{\circ} \mathrm{C}$ for $3 \mathrm{~h}$. The mixture was then stirred at $\mathrm{rt} 30 \mathrm{~min}$ under air. The mixture was filtered through silica gel $(160 \mathrm{~g})$ and was eluted with $\mathrm{CH}_{2} \mathrm{Cl}_{2}(100 \mathrm{~mL})$ then EtOAc/hexane $(1 / 1,600 \mathrm{~mL})$. The EtOAc/hexane filtrate was collected and the solvent was removed. The crude mixture was purified by silica gel chromatography using EtOAc/hexane (3/17 to 3/7) as the eluent to give $5.15 \mathrm{~g}$ of $\mathbf{2 2}(85 \%)$ as a sticky oil. $[\alpha]_{\mathrm{D}}{ }^{20}:-33.7^{\circ}\left(\mathrm{c}=1.6, \mathrm{CHCl}_{3}\right) .{ }^{1} \mathrm{H} \mathrm{NMR}\left(\mathrm{CDCl}_{3}, 300 \mathrm{MHz}\right) \delta 7.76(\mathrm{~d}, J=9.0 \mathrm{~Hz}, 2 \mathrm{H})$, 7.56-7.25 (m, $21 \mathrm{H}), 5.80(\mathrm{~d}, J=6.0 \mathrm{~Hz}, 1 \mathrm{H}, \mathrm{NH}), 5.64(\mathrm{dt}, J=12.0,3.0 \mathrm{~Hz}, 1 \mathrm{H}), 5.53-$ $5.47(\mathrm{~m}, 1 \mathrm{H}), 4.46-4.23(\mathrm{~m}, 4 \mathrm{H}), 4.16(\mathrm{t}, J=6.0 \mathrm{~Hz}, 1 \mathrm{H}), 3.85(\mathrm{dd}, J=18.0,9.0 \mathrm{~Hz}, 1$ H), 2.48 (br d, $J=15.0 \mathrm{~Hz}, 1 \mathrm{H}), 1.91$ (br t, $J=15.0 \mathrm{~Hz}, 1 \mathrm{H}) .{ }^{13} \mathrm{C} \mathrm{NMR}\left(\mathrm{CDCl}_{3}, 75\right.$ MHz) $\delta 170.3,155.3$, (143.9, 143.8), 142.5, 141.3, 129.9, 129.8, 127.9, 127.7, 127.5, 127.1, 125.2, 122.6, 120.0, 94.6, 66.9, 51.1, 50.2, 47.1, 32.5. MS ( $\mathrm{m} / \mathrm{z}) 629\left(\mathrm{M}^{+}+\mathrm{Na}, 30\right)$, 467 (30), 297 (35), 243 (100). Anal. Calcd for $\mathrm{C}_{40} \mathrm{H}_{34} \mathrm{~N}_{2} \mathrm{O}_{4}$ : C, 79.19; H, 5.65; N, 4.62. Found: C, 79.10; H, 5.80; N, 4.51. 
Preparation of (24)

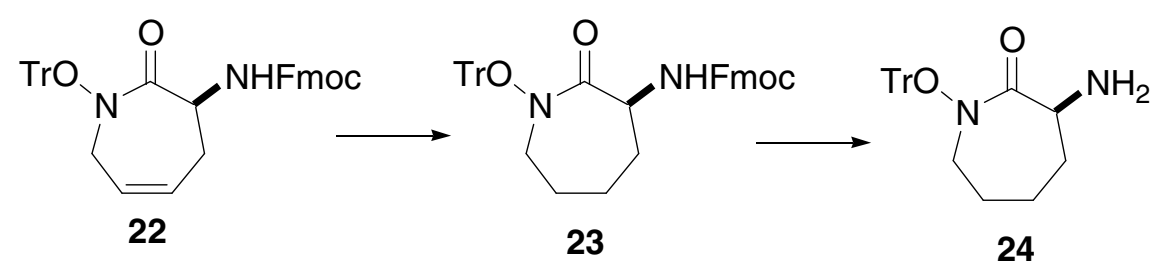

To a solution of $22(3.03 \mathrm{~g}, 5.0 \mathrm{mmol})$ in EtOAc $(50 \mathrm{~mL})$ was added $5 \mathrm{wt} \% \mathrm{Pt} / \mathrm{C}(1.0 \mathrm{~g}$, $0.25 \mathrm{mmol}$ of Pt loading, 0.05 equiv). The container was fixed into PARR shaker. The air was removed and was refilled with $\mathrm{H}_{2}$ for three times. The container was shaken at room temperature for $1.5 \mathrm{~h}$ under $\mathrm{H}_{2}(15 \mathrm{psi})$. The mixture was then filtered through a short path of silica gel which was eluted with EtOAc. The filtrate was collected and concentrated. The crude product (23) was dissolved in $\mathrm{MeCN}(20 \mathrm{~mL})$ and $\mathrm{Et}_{3} \mathrm{~N}(2.1 \mathrm{~mL}$, $15 \mathrm{mmol}, 3.0$ equiv) was added. The mixture was stirred at $\mathrm{rt}$ for $12 \mathrm{~h}$ and was then poured into a mixture of EtOAc $(100 \mathrm{~mL})$ and brine $(100 \mathrm{~mL})$. The organic layer was dried $\left(\mathrm{Na}_{2} \mathrm{SO}_{4}\right)$ and filtered. After removal of solvent, the crude mixture was purified by silica gel chromatography using EtOAc/hexane (1/1 to 1/0), then MeOH/EtOAc (1/9) as the eluent to give $2.62 \mathrm{~g}$ of $\mathbf{2 4}(68 \%$, two steps $)$ as a white solid. $[\alpha]_{\mathrm{D}}{ }^{20}:+27.6^{\circ}(\mathrm{c}=1.2$, $\left.\mathrm{CHCl}_{3}\right) .{ }^{1} \mathrm{H} \mathrm{NMR}\left(\mathrm{CDCl}_{3}, 300 \mathrm{MHz}\right) \delta$ 7.47-7.43 (m, $\left.6 \mathrm{H}\right)$, 7.34-7.26 (m, $\left.9 \mathrm{H}\right), 3.58$ (dd, $J=18.0,3.0 \mathrm{~Hz}, 1 \mathrm{H}), 3.24(\mathrm{ddd}, J=15.0,9.0,3.0 \mathrm{~Hz}, 1 \mathrm{H}), 3.03(\mathrm{~d}, J=9.0 \mathrm{~Hz}, 1 \mathrm{H})$, $1.85(\mathrm{~d}, J=12.0 \mathrm{~Hz}, 1 \mathrm{H}), 1.69(\mathrm{~d}, J=15.0 \mathrm{~Hz}, 1 \mathrm{H}), 1.62-1.33(\mathrm{~m}, 6 \mathrm{H}) .{ }^{13} \mathrm{C} \mathrm{NMR}$ $\left(\mathrm{CDCl}_{3}, 75 \mathrm{MHz}\right) \delta 175.3,142.9,130.0,127.7,127.3,94.0,53.5,53.3,32.9,27.6,26.2$. MS (m/z) $795\left(2 \mathrm{M}^{+}+\mathrm{Na}, 20\right), 409\left(\mathrm{M}^{+}+\mathrm{Na}, 5\right), 243(100)$. Anal. Calcd for $\mathrm{C}_{25} \mathrm{H}_{24} \mathrm{~N}_{2} \mathrm{O}_{2}: \mathrm{C}$, 78.10; H, 6.29; N, 7.29. Found: C, 77.73; H, 6.70; N, 7.22.

Synthesis of (-)-Cobactin T (18).

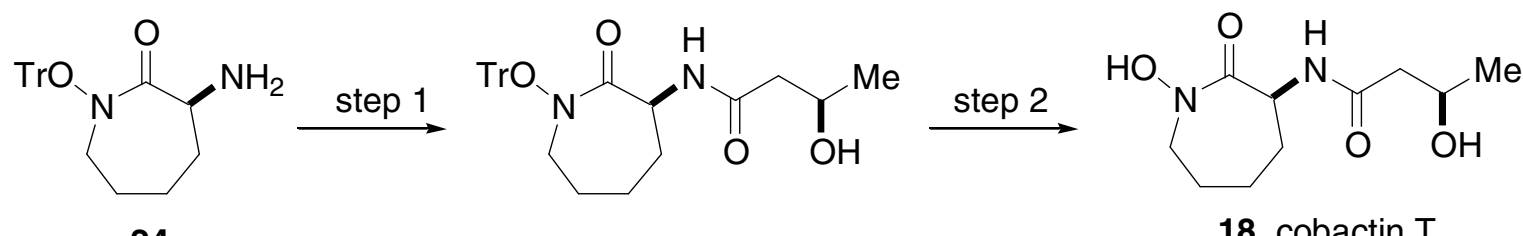

24

18, cobactin $T$

\section{Step 1:}


To a mixture of ( $R$ )-3-hydroxybutyric acid (572 mg, $5.5 \mathrm{mmol}, 1.1$ equiv), EDC (1.43 g, $7.5 \mathrm{mmol}, 1.5$ equiv), HOAt (748 mg, $5.5 \mathrm{mmol}, 1.1$ equiv) was added $\mathrm{CHCl}_{3}(25 \mathrm{~mL})$, $N$-methylmorpholine (1.43 mL, $13 \mathrm{mmol}, 2.6$ equiv), and then $24(1.93 \mathrm{~g}, 5.0 \mathrm{mmol})$ sequentially at room temperature. The mixture was stirred at $\mathrm{rt}$ for $\mathrm{h}$ and was then poured into EtOAc/ $\mathrm{H}_{2} \mathrm{O}(100 \mathrm{~mL} / 100 \mathrm{~mL})$. The organic layer was separated and was washed with brine $(100 \mathrm{~mL})$, dried $\left(\mathrm{Na}_{2} \mathrm{SO}_{4}\right)$, and then filtered. After removal of solvent, the product was purified by silica gel chromatography using EtOAc/hexane (3/7-7/3) as the eluent to give $1.65 \mathrm{~g}$ of trityl-protected Cobactin T $25(70 \%)$ as a oil. $[\alpha]_{\mathrm{D}}{ }^{20}:+3.2^{\circ}(\mathrm{c}=$ 1.2, $\left.\mathrm{CHCl}_{3}\right) .{ }^{1} \mathrm{H} \mathrm{NMR}\left(\mathrm{CDCl}_{3}, 300 \mathrm{MHz}\right) \delta$ 7.34-7.19 (m, $\left.15 \mathrm{H}\right), 6.67$ (d, $J=6.0 \mathrm{~Hz}, 1$ H, NH), 4.17-4.02 (m, 2 H), 3.57 (dd, $J=15.0,3.0 \mathrm{~Hz}, 1 \mathrm{H}$ ), 3.27 (dd, $J=15.0,9.0 \mathrm{~Hz}, 1$ H), $2.25(\mathrm{dd}, J=15.0,3.0 \mathrm{~Hz}, 1 \mathrm{H}), 2.16(\mathrm{dd}, J=15.0,6.0 \mathrm{~Hz}, 1 \mathrm{H}), 1.92-1.87(\mathrm{~m}, 2 \mathrm{H})$, 1.70-1.50 (m, $3 \mathrm{H}), 1.46-1.35$ (m, $1 \mathrm{H}), 1.25$ (d, $J=6.0 \mathrm{~Hz}, 3 \mathrm{H}) .{ }^{13} \mathrm{C} \mathrm{NMR}\left(\mathrm{CDCl}_{3}, 75\right.$ MHz) $\delta 171.3,170.7,142.5,129.8,127.9,127.5,94.5,64.8,53.4,51.2,43.5,31.1,27.3$, 25.8, 22.5. MS $(\mathrm{m} / \mathrm{z}) 495\left(\mathrm{M}^{+}+\mathrm{Na}, 35\right), 243(100)$. HRMS Calcd for $\mathrm{C}_{29} \mathrm{H}_{32} \mathrm{~N}_{2} \mathrm{O}_{4} \mathrm{Na}$ $\left(\mathrm{M}^{+}+\mathrm{Na}\right)$ : 495.2260. Found: 495.2263.

\section{Step 2:}

Method A: According to the General Procedure II, the trityl-protected Cobactin 25 (472 $\mathrm{mg}, 1.0 \mathrm{mmol}), \mathrm{BF}_{3} \cdot \mathrm{OEt}_{2}(0.25 \mathrm{~mL}, 2.0 \mathrm{mmol})$, and $\mathrm{CH}_{2} \mathrm{Cl}_{2} / \mathrm{MeOH}(8 \mathrm{~mL} / 2 \mathrm{~mL})$ were combined. The mixture was stirred at $\mathrm{rt}$ for $15 \mathrm{~min}$ and was poured into $\mathrm{EtOAc} / \mathrm{H}_{2} \mathrm{O}(50$ $\mathrm{mL} / 50 \mathrm{~mL})$. The aqueous layer was extracted with EtOAc $(50 \mathrm{~mL} \times 2)$. The combined organic layer was dried $\left(\mathrm{Na}_{2} \mathrm{SO}_{4}\right)$ and filtered. The crude product was purified by silica gel chromatography using EtOAc/hexane (3/7 to 7/3) as the eluent to give $103 \mathrm{mg}$ of (-)Cobactin T (18) (45\%) as a white solid.

Method B: To a mixture of 25 (472 mg, $1.0 \mathrm{mmol})$ and Amberlyst ${ }^{\circledR} 15$ ionexchange resin $(1.0 \mathrm{~g})$ was added $\mathrm{CH}_{2} \mathrm{Cl}_{2} / \mathrm{MeOH}(2.0 \mathrm{~mL} / 8.0 \mathrm{~mL})$. The mixture was stirred at room temperature for $2 \mathrm{~h}$. The mixture was then filtered and was washed with EtOAc $(10 \mathrm{~mL})$. The filtrate was concentrated and the product was recrystallized from EtOAc/hexane to give $184 \mathrm{mg}$ of (-)-Cobactin $\mathrm{T}(\mathbf{1 8})(80 \%)$ as a white solid. mp. 137-139 ${ }^{\circ} \mathrm{C}$ (lit. 137- 
$\left.138.5^{\circ} \mathrm{C}\right)^{1} \cdot[\alpha]_{\mathrm{D}}^{20}:-87.9^{\circ}\left(\mathrm{c}=1, \mathrm{H}_{2} \mathrm{O}\right)\left\{\right.$ lit. $[\alpha]_{\mathrm{D}}^{23}:-90.5^{\circ}\left(\mathrm{c}=1.5, \mathrm{H}_{2} \mathrm{O}\right)$ and $[\alpha]_{\mathrm{D}}^{23}$ : $\left.-88.9^{\circ}\right\}^{1} .{ }^{1} \mathrm{H} \mathrm{NMR}\left(\mathrm{CDCl}_{3}, 300 \mathrm{MHz}\right) \delta 7.03(\mathrm{~d}, J=6.0 \mathrm{~Hz}, 1 \mathrm{H}, \mathrm{NH}), 4.61(\mathrm{ddd}, J=$ 11.4, 6.9, $1.5 \mathrm{~Hz}, 1 \mathrm{H}), 4.18$ (dtd, $J=15.6,6.6,3.3 \mathrm{~Hz}, 1 \mathrm{H}), 3.84-3.70(\mathrm{~m}, 2 \mathrm{H}), 2.44$ $(\mathrm{dd}, J=15.6,3.0 \mathrm{~Hz}, 1 \mathrm{H}), 2.32(\mathrm{dd}, J=15.0,8.4 \mathrm{~Hz}, 1 \mathrm{H}), 2.05-1.99(\mathrm{~m}, 2 \mathrm{H}), 1.86-1.72$ $(\mathrm{m}, 2 \mathrm{H}), 1.64-1.42(\mathrm{~m}, 2 \mathrm{H}), 1.22(\mathrm{~d}, J=6.3 \mathrm{~Hz}, 3 \mathrm{H}) .{ }^{13} \mathrm{C} \mathrm{NMR}\left(\mathrm{CDCl}_{3}, 75 \mathrm{MHz}\right)$ $\delta 171.63,167.35,64.79,50.86,50.63,43.77,31.12,27.70,25.69,22.61 . \mathrm{MS}(\mathrm{m} / \mathrm{z}) 483$ $\left(2 \mathrm{M}^{+}+\mathrm{Na}, 10\right), 253\left(\mathrm{M}^{+}+\mathrm{Na}, 40\right), 231\left(\mathrm{M}^{+}+1,45\right), 118(90)$.

\footnotetext{
${ }^{1}$ Maurer, P. J.; Miller, M. J. J. Am. Chem. Soc. 1983, 105, 240.
} 


\section{NMR Spectra of Representative Compounds}

${ }^{1} \mathrm{H}$ NMR spectra of $\mathbf{1 a}\left(\mathrm{d}_{6}-\mathrm{DMSO}, 300 \mathrm{MHz}\right)$.
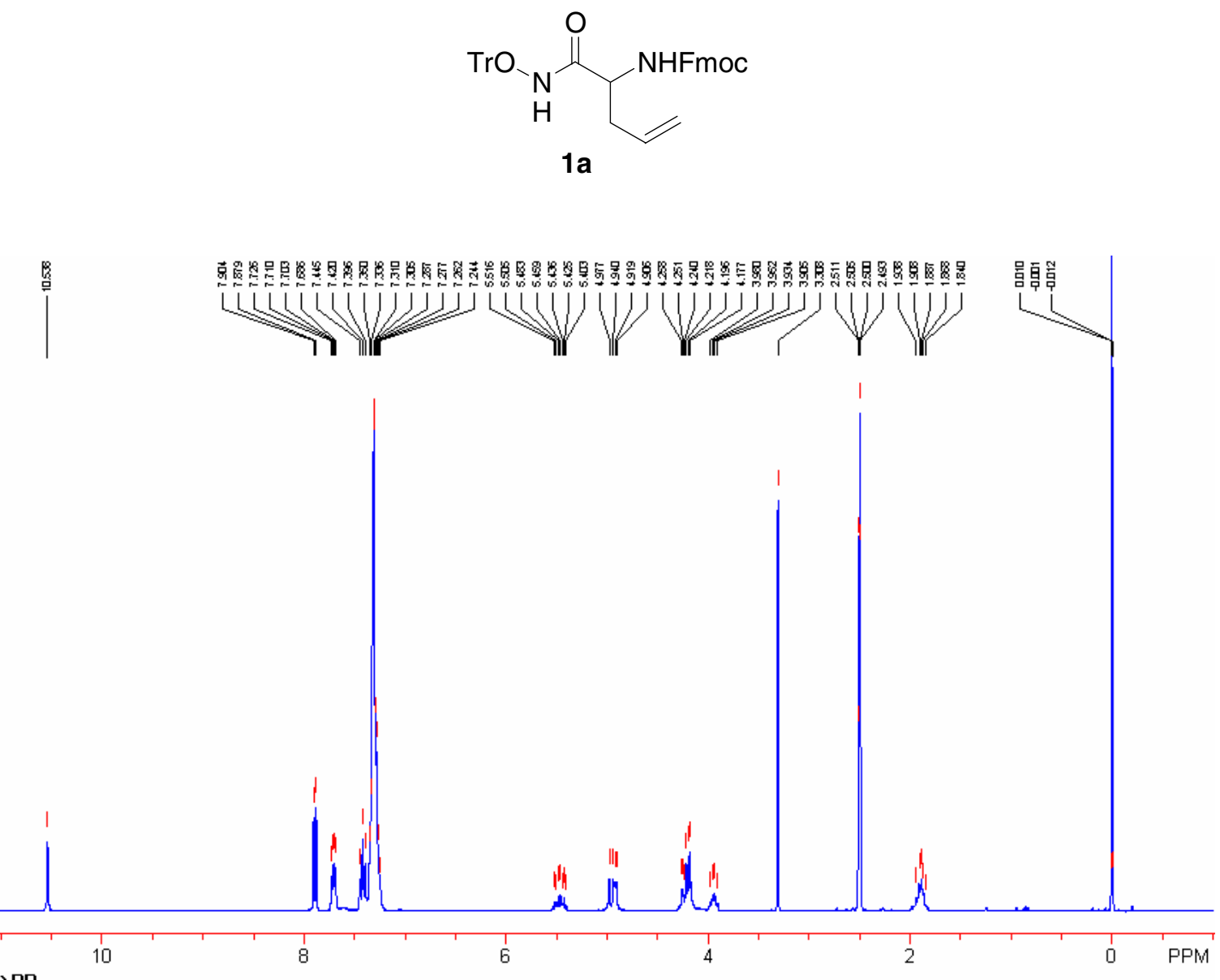
${ }^{1} \mathrm{H}$ NMR spectra of $\mathbf{1} \mathbf{b}\left(\mathrm{d}_{6}\right.$-DMSO, $\left.300 \mathrm{MHz}\right)$.
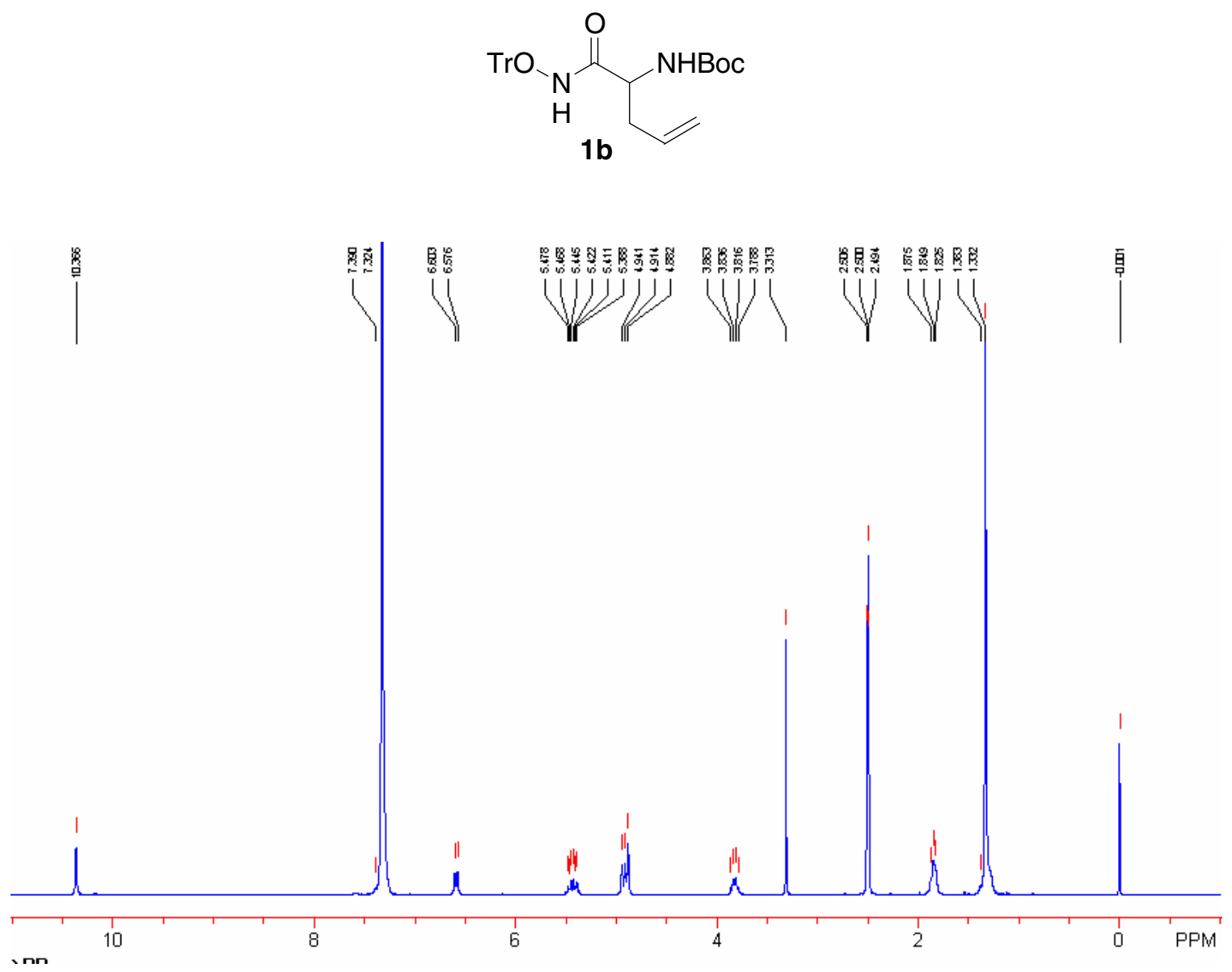
${ }^{1} \mathrm{H}$ NMR spectra of $1 \mathbf{c}\left(\mathrm{d}_{6}-\mathrm{DMSO}, 300 \mathrm{MHz}\right)$.
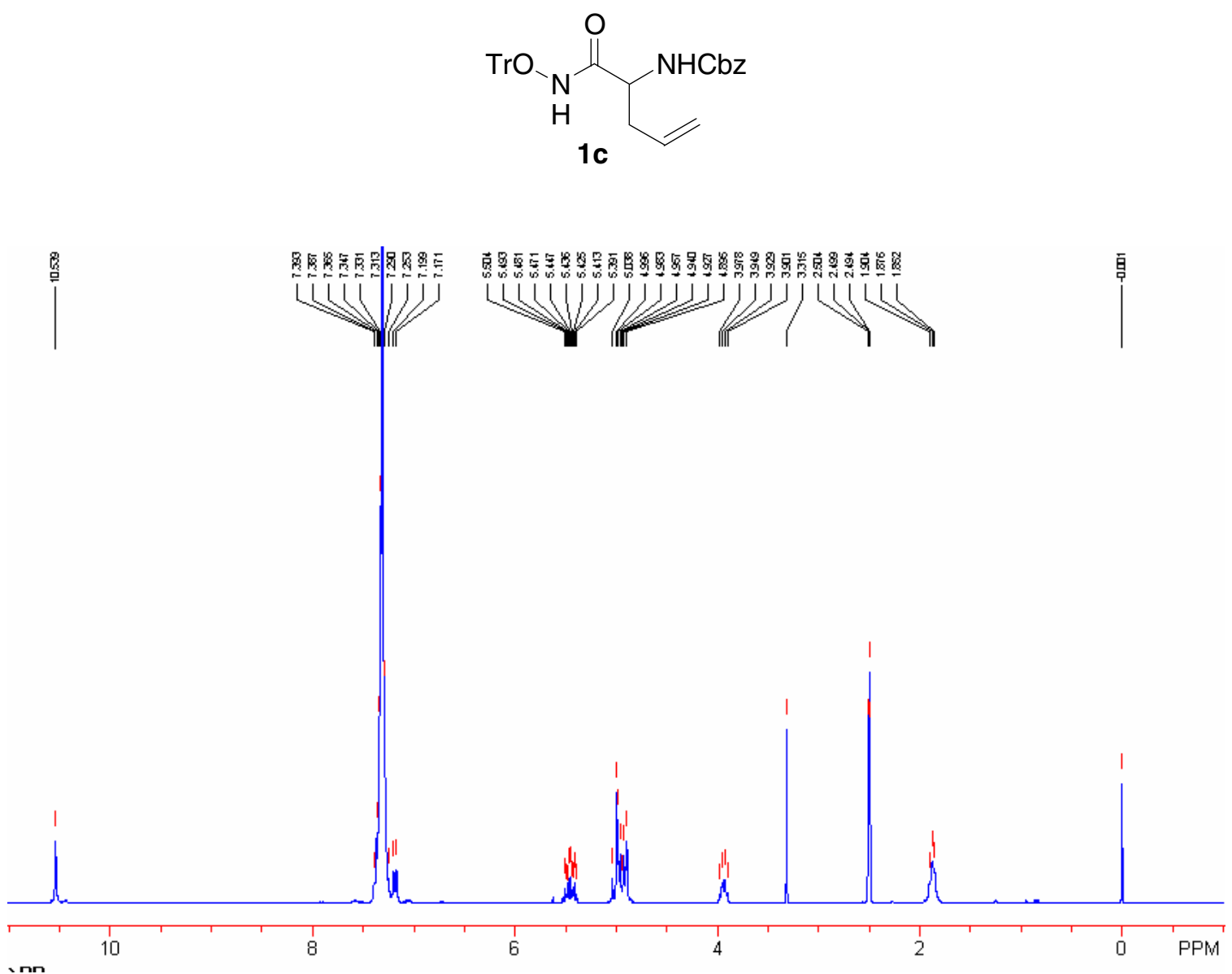
${ }^{1} \mathrm{H}$ NMR spectra of $29\left(\mathrm{CDCl}_{3}, 300 \mathrm{MHz}\right)$.
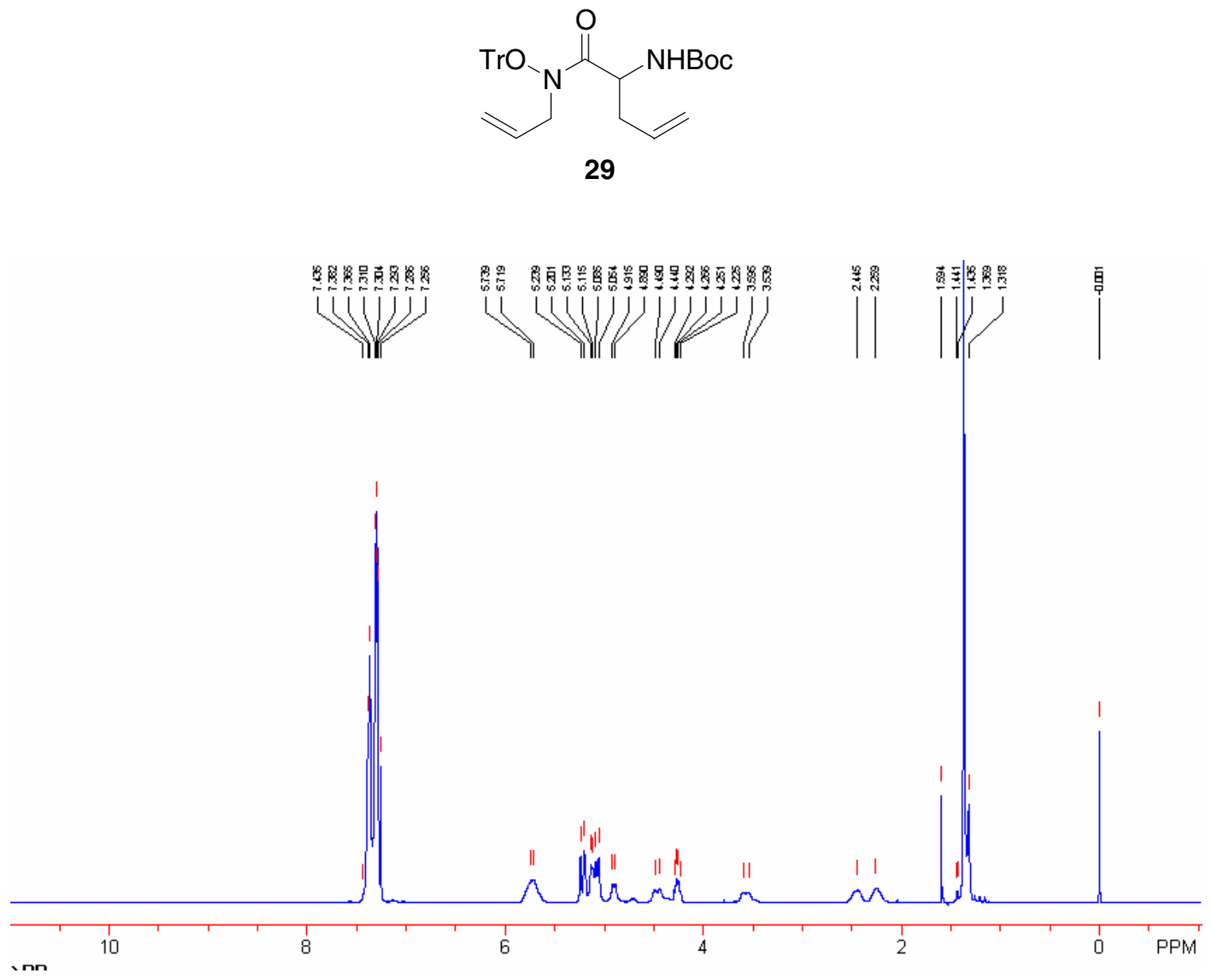
${ }^{1} \mathrm{H}$ NMR spectra of $2\left(\mathrm{CDCl}_{3}, 300 \mathrm{MHz}\right)$.
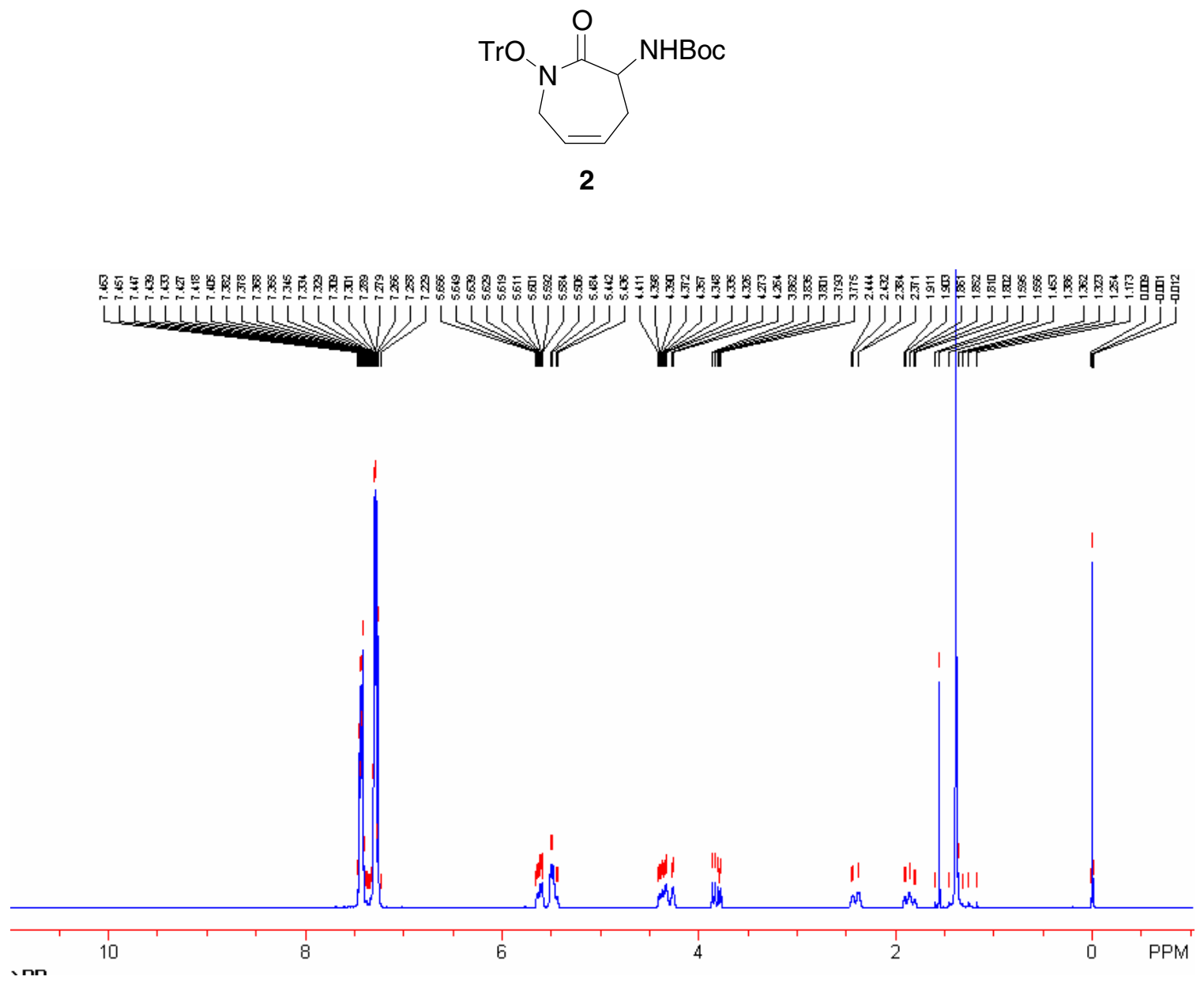
${ }^{1} \mathrm{H}$ NMR spectra of $\mathbf{3}\left(\mathrm{CDCl}_{3}, 400 \mathrm{MHz}\right)$.
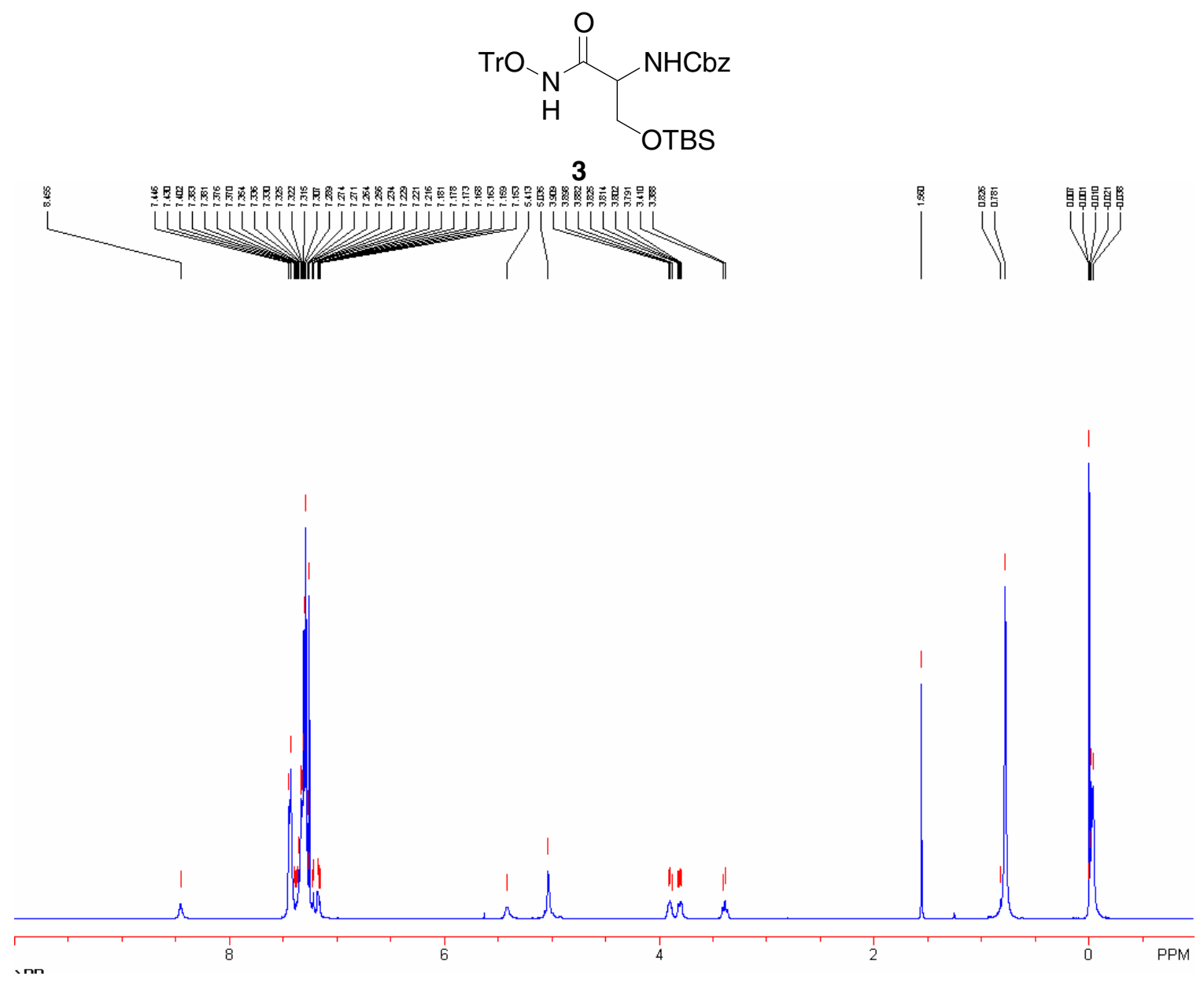
${ }^{1} \mathrm{H}$ NMR spectra of $4\left(\mathrm{~d}_{6}\right.$-DMSO, $\left.300 \mathrm{MHz}\right)$.
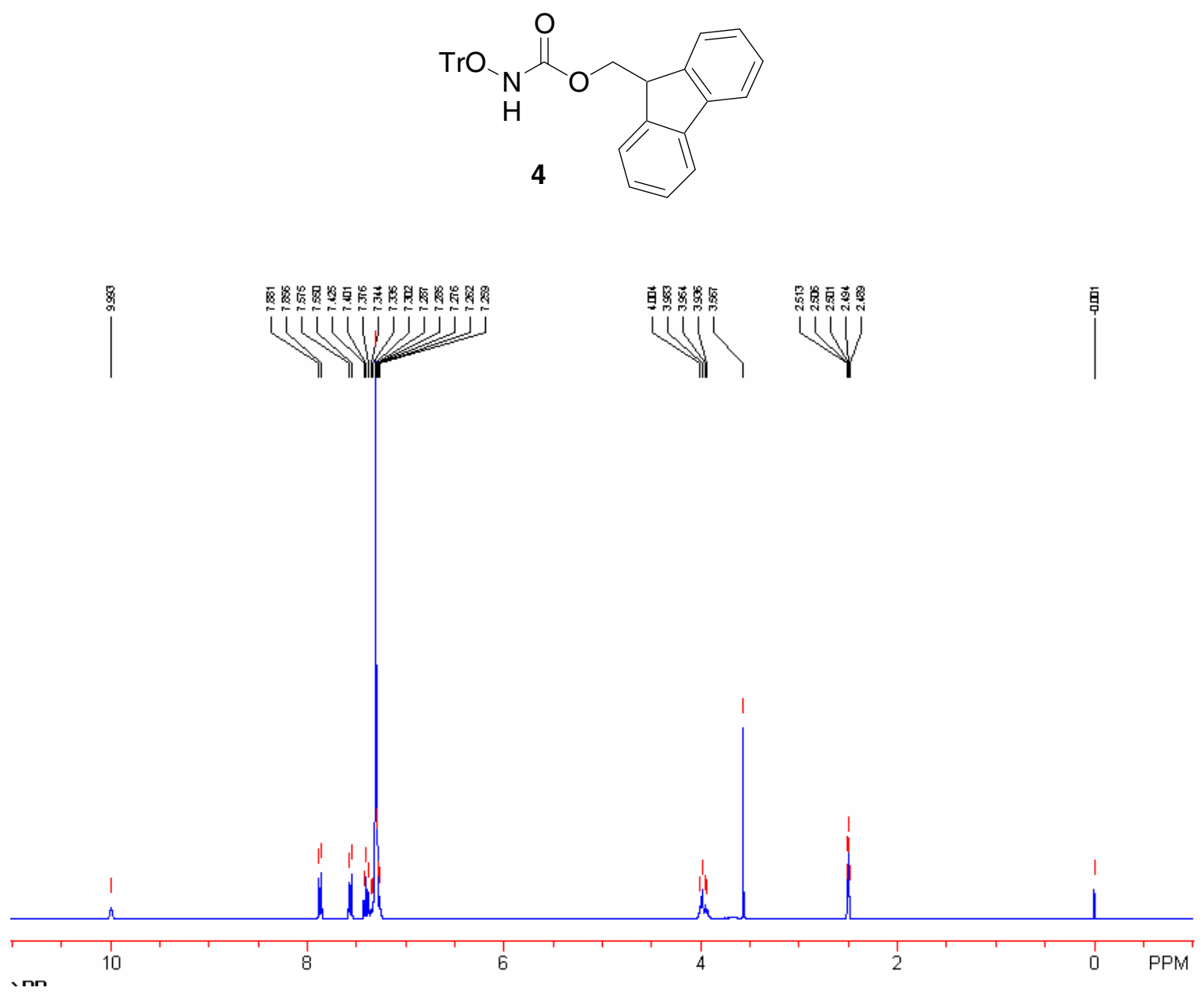
${ }^{1} \mathrm{H}$ NMR spectra of $\mathbf{6}\left(\mathrm{CDCl}_{3}, 300 \mathrm{MHz}\right)$.
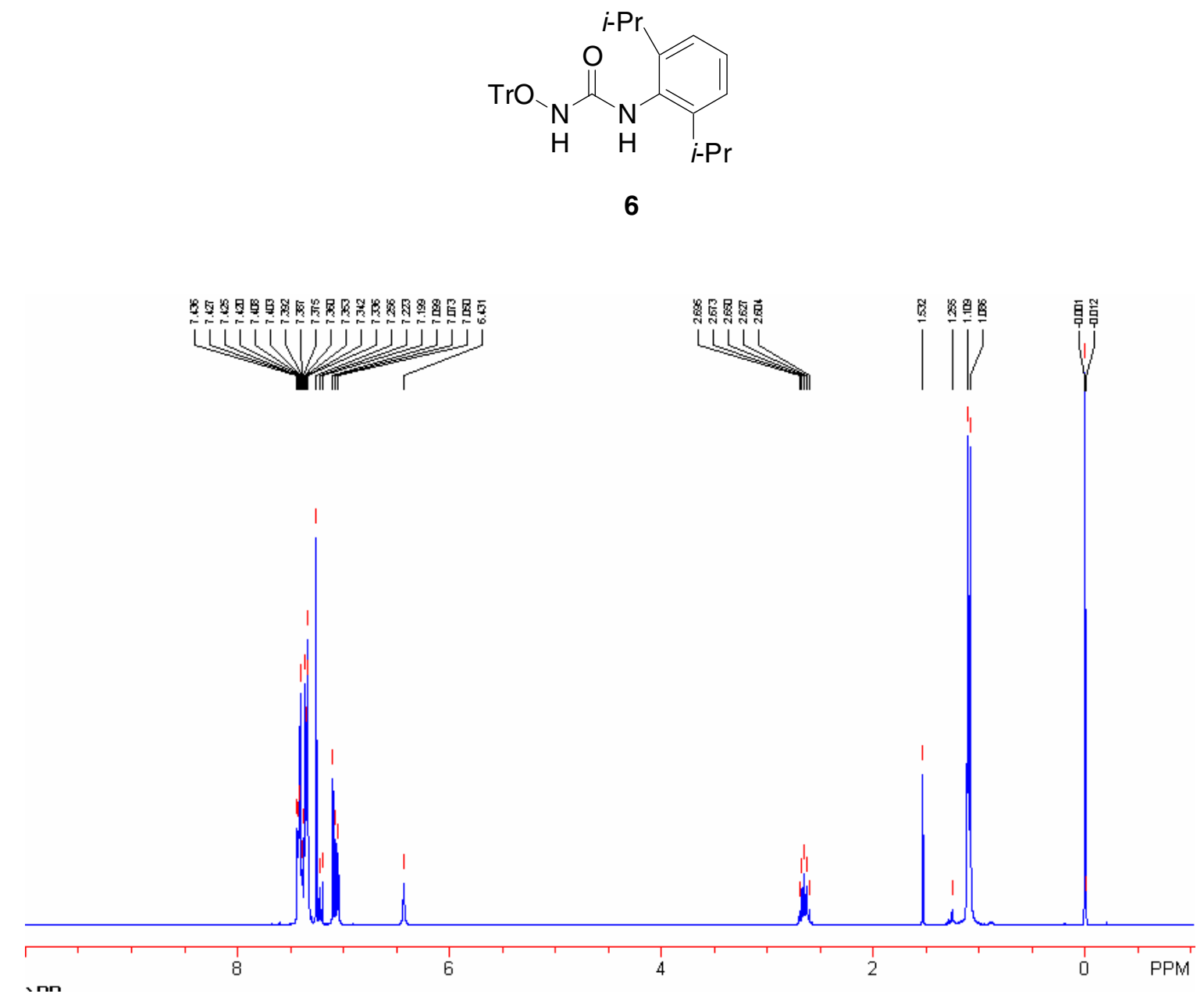
${ }^{1} \mathrm{H}$ NMR spectra of $7\left(\mathrm{CDCl}_{3}, 300 \mathrm{MHz}\right)$.
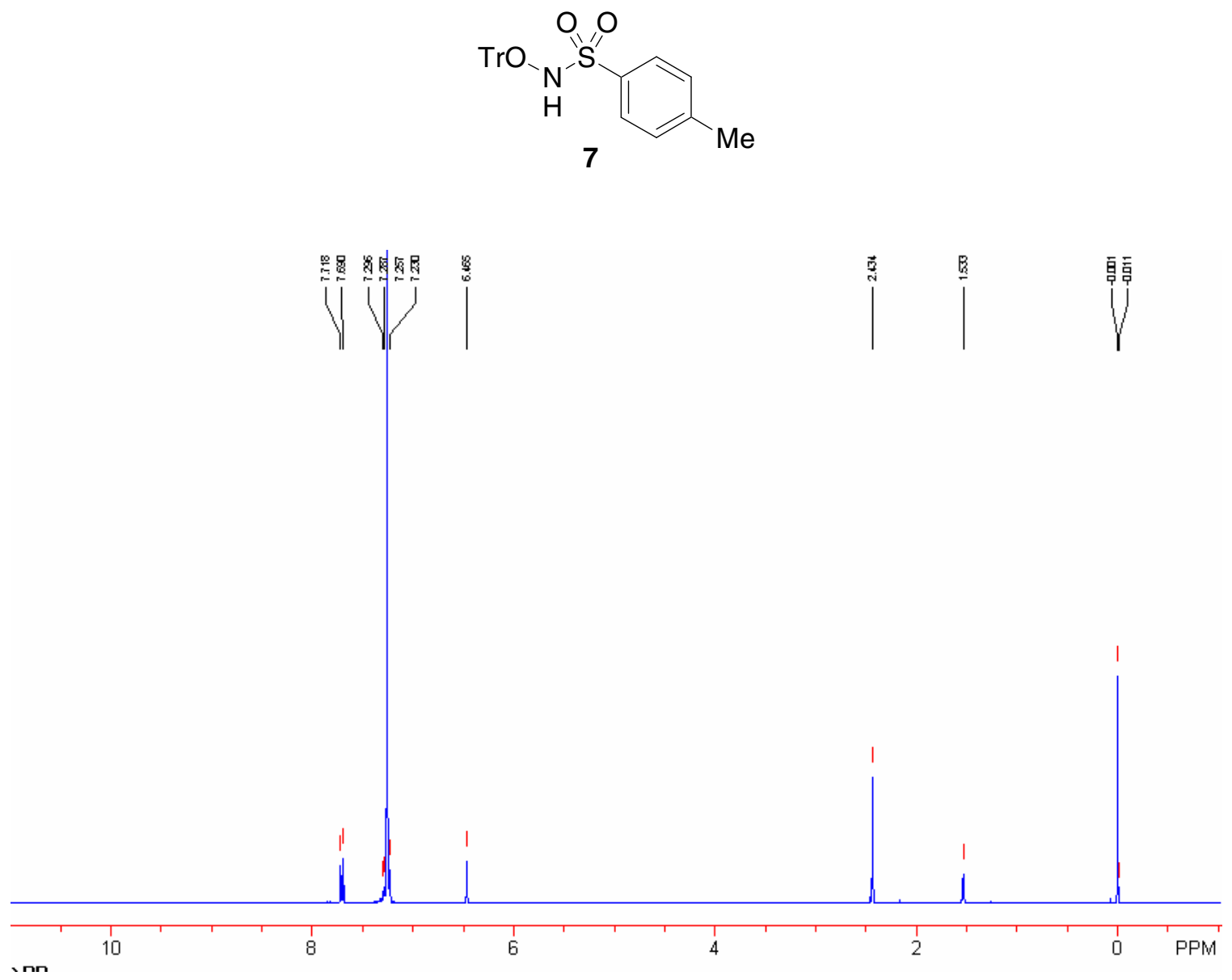
${ }^{1} \mathrm{H}$ NMR spectra of $\mathbf{3 4}\left(\mathrm{CDCl}_{3}, 300 \mathrm{MHz}\right)$.<smiles>C=CCOC(=NO)C(CC=C)N=CO</smiles>
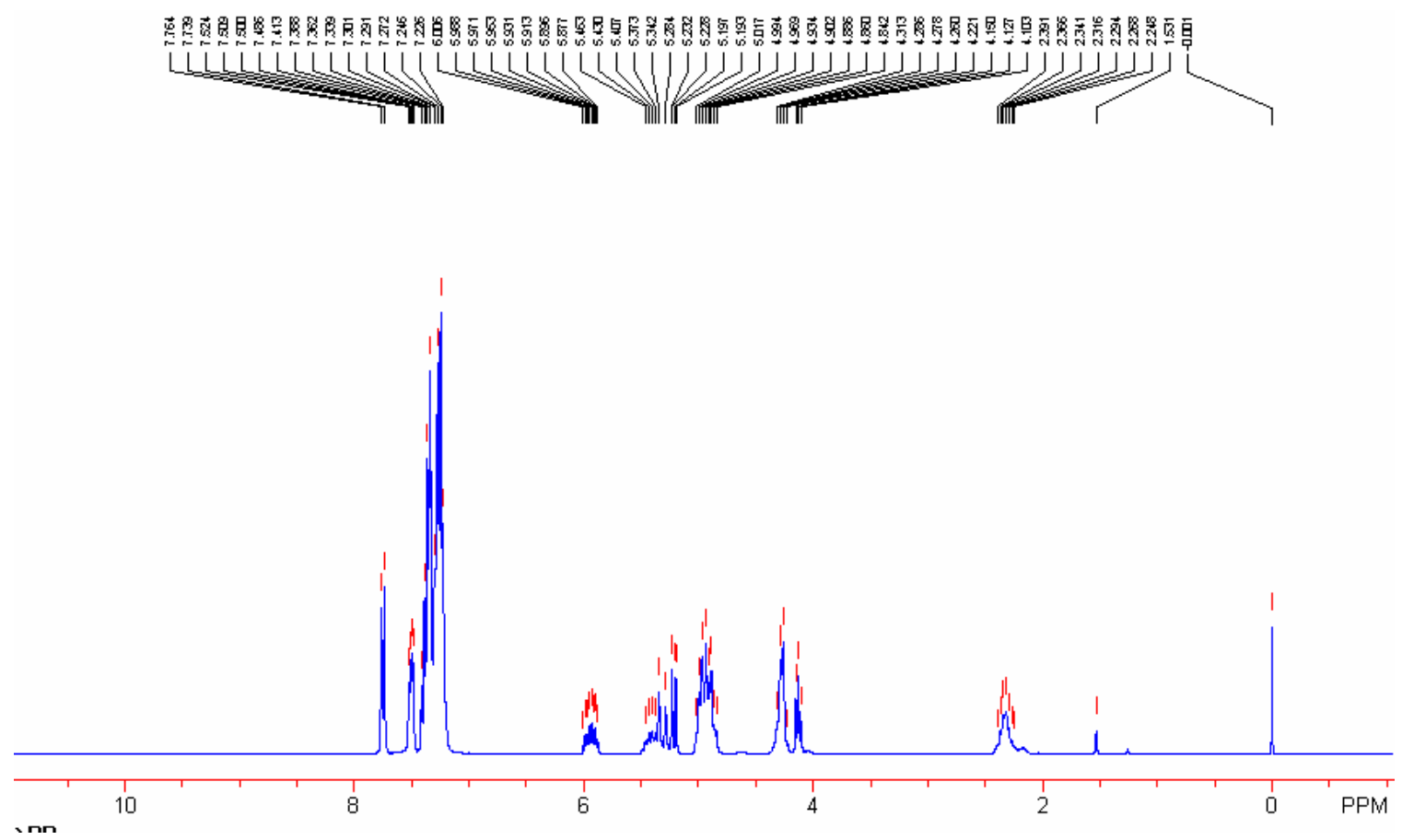
${ }^{1} \mathrm{H}$ NMR spectra of 9a $\left(\mathrm{d}_{6}\right.$-DMSO, $\left.300 \mathrm{MHz}\right)$.
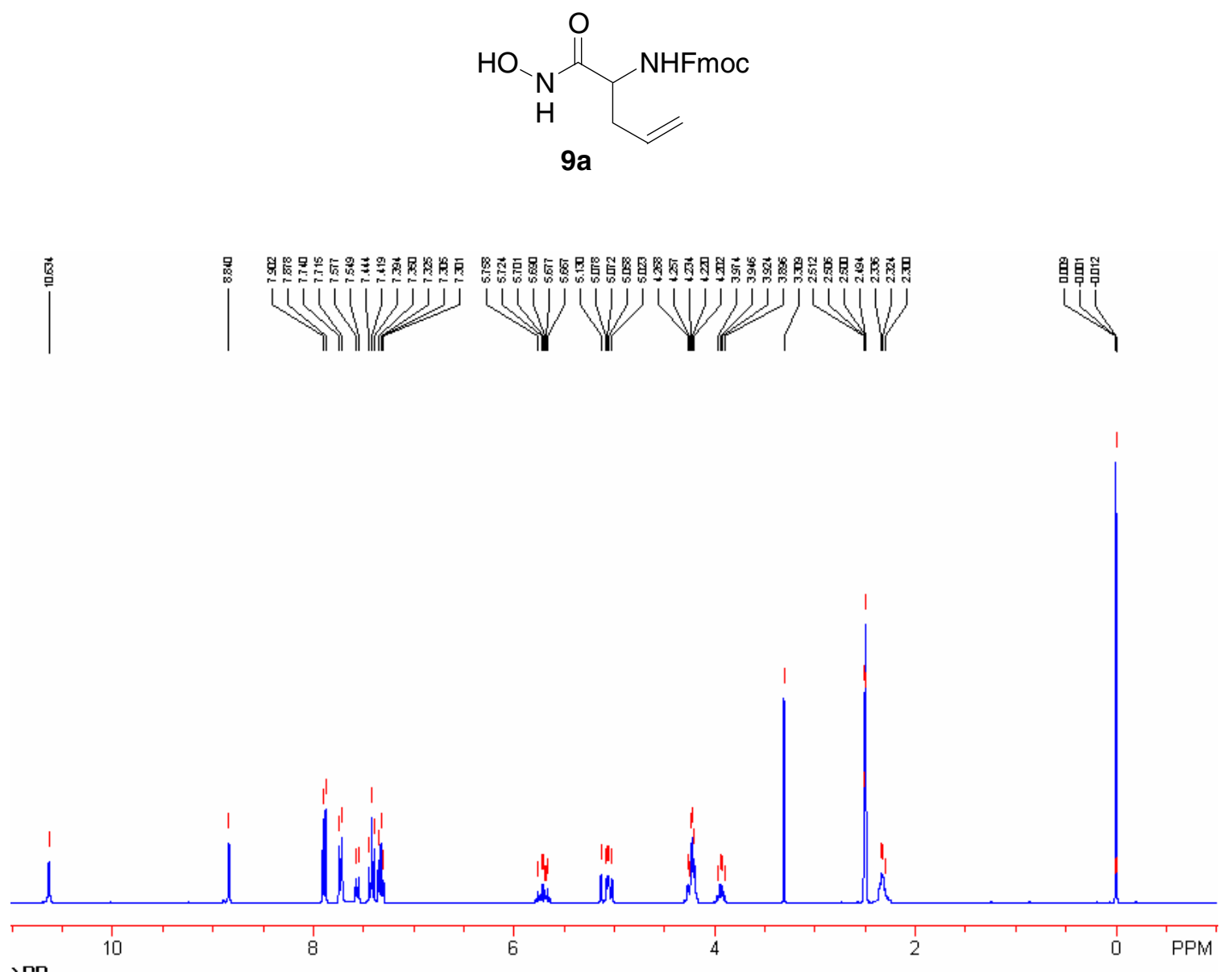
${ }^{1} \mathrm{H}$ NMR spectra of $\mathbf{9 b}\left(\mathrm{d}_{6}\right.$-acetone, $\left.400 \mathrm{MHz}\right)$.
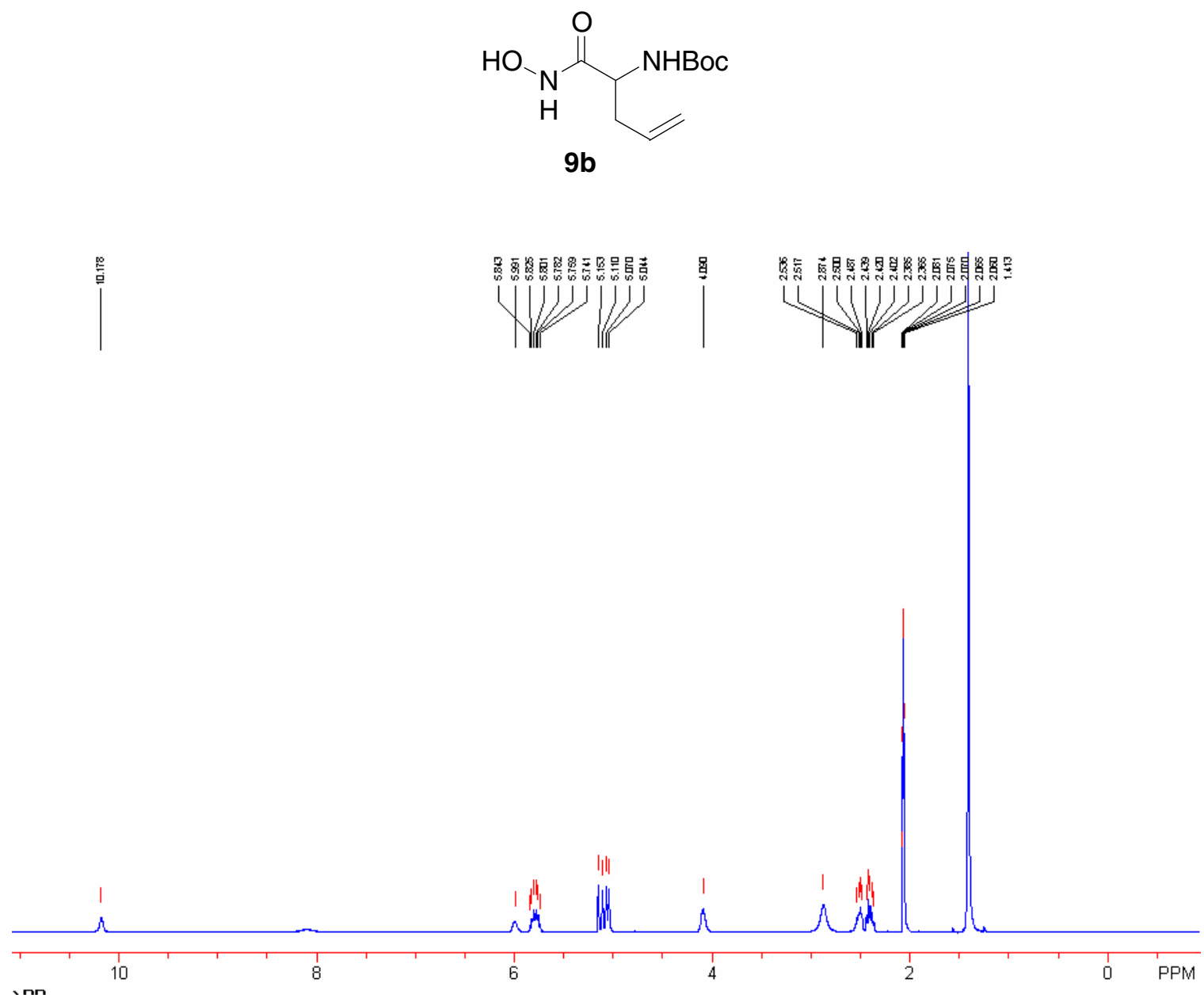
${ }^{1} \mathrm{H}$ NMR spectra of 9c $\left(\mathrm{d}_{6}\right.$-DMSO, $\left.300 \mathrm{MHz}\right)$.
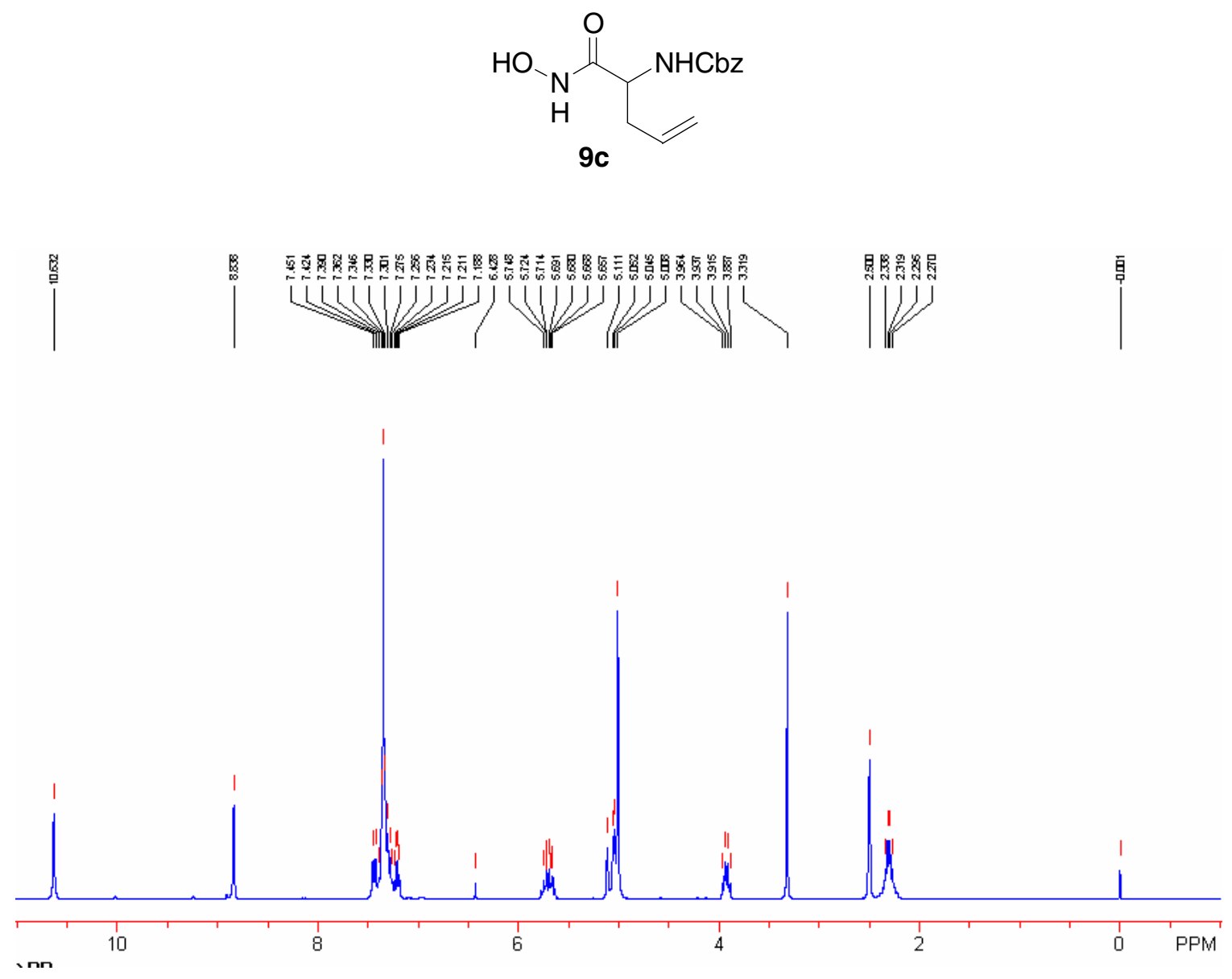
${ }^{1} \mathrm{H}$ NMR spectra of $\mathbf{1 0}\left(\mathrm{CDCl}_{3}, 300 \mathrm{MHz}\right)$.

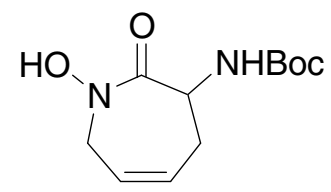

10
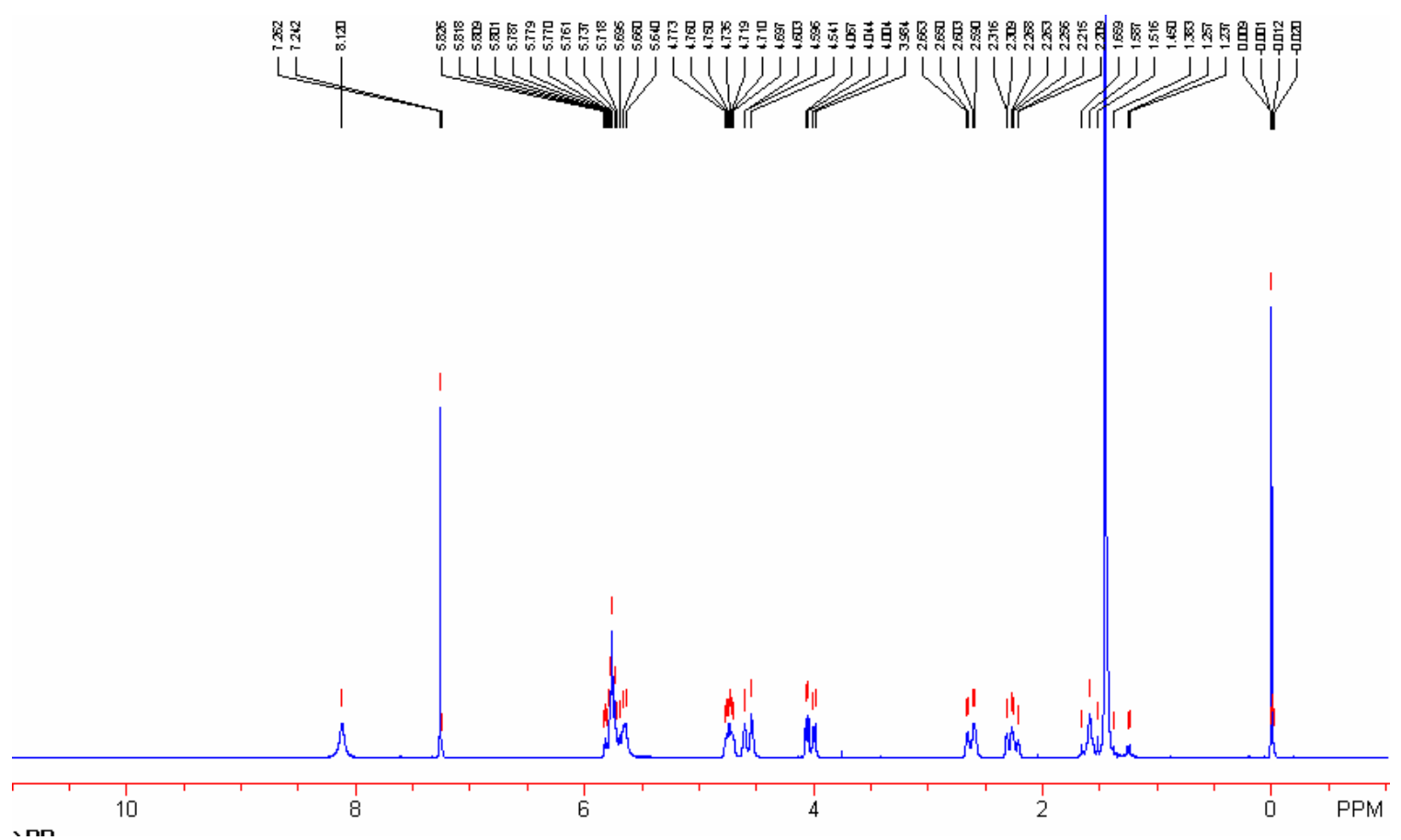
${ }^{1} \mathrm{H}$ NMR spectra of $\mathbf{1 1}\left(\mathrm{d}_{6}\right.$-acetone, $\left.300 \mathrm{MHz}\right)$.
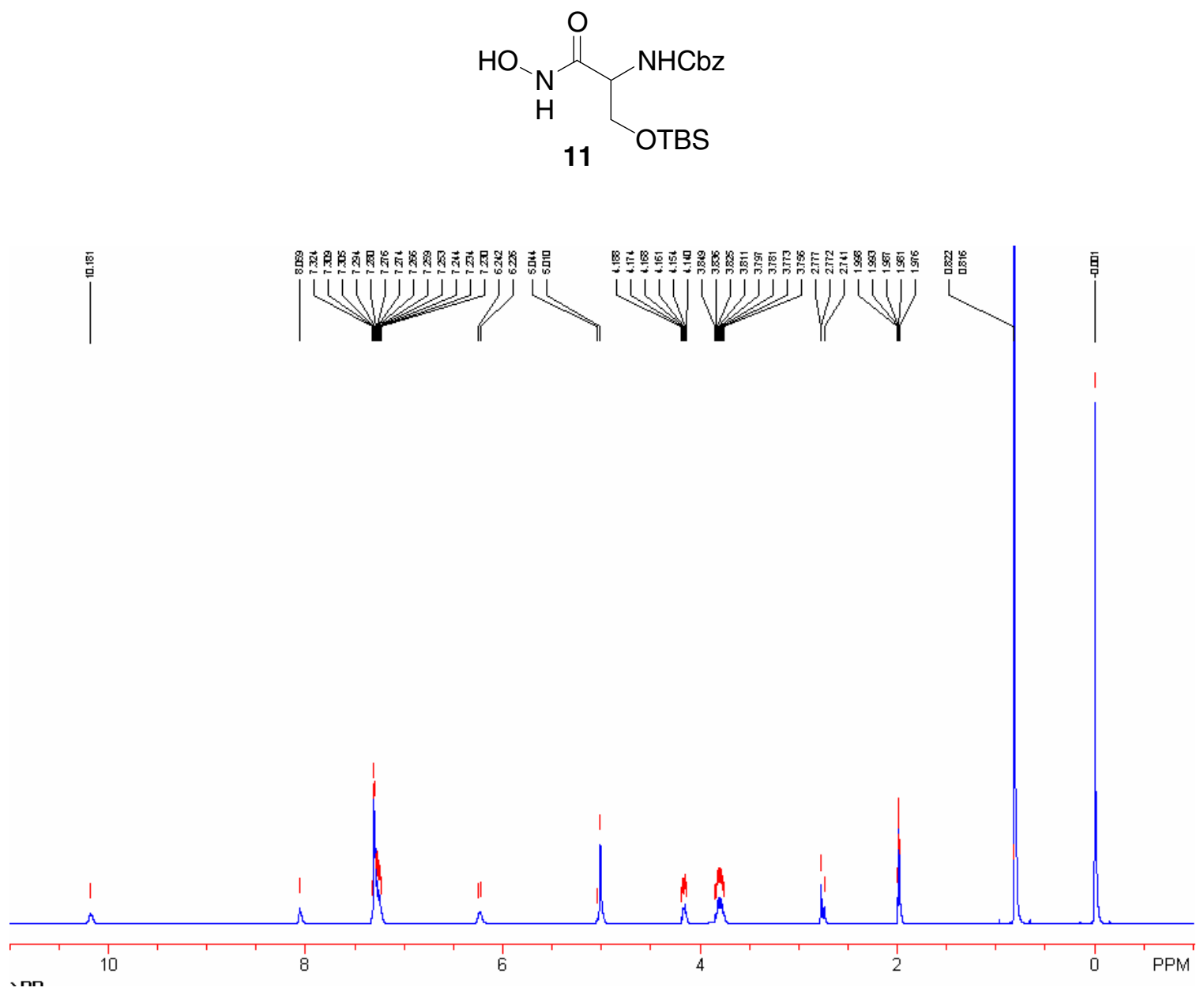
${ }^{1} \mathrm{H}$ NMR spectra of $\mathbf{1 2}\left(\mathrm{d}_{6}\right.$-DMSO, $\left.300 \mathrm{MHz}\right)$.
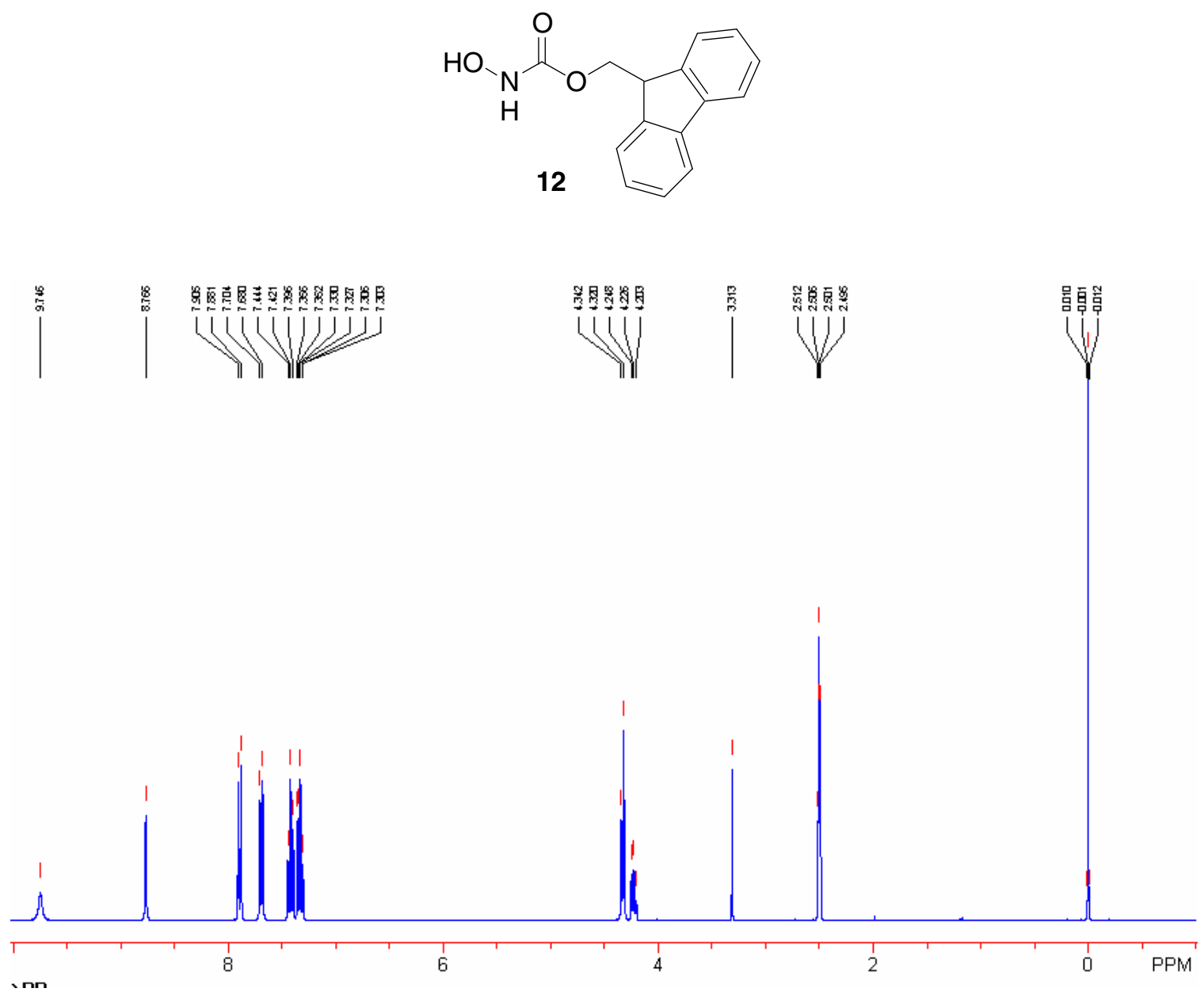
${ }^{1} \mathrm{H}$ NMR spectra of $\mathbf{1 3}\left(\mathrm{d}_{6}\right.$-DMSO, $\left.300 \mathrm{MHz}\right)$.
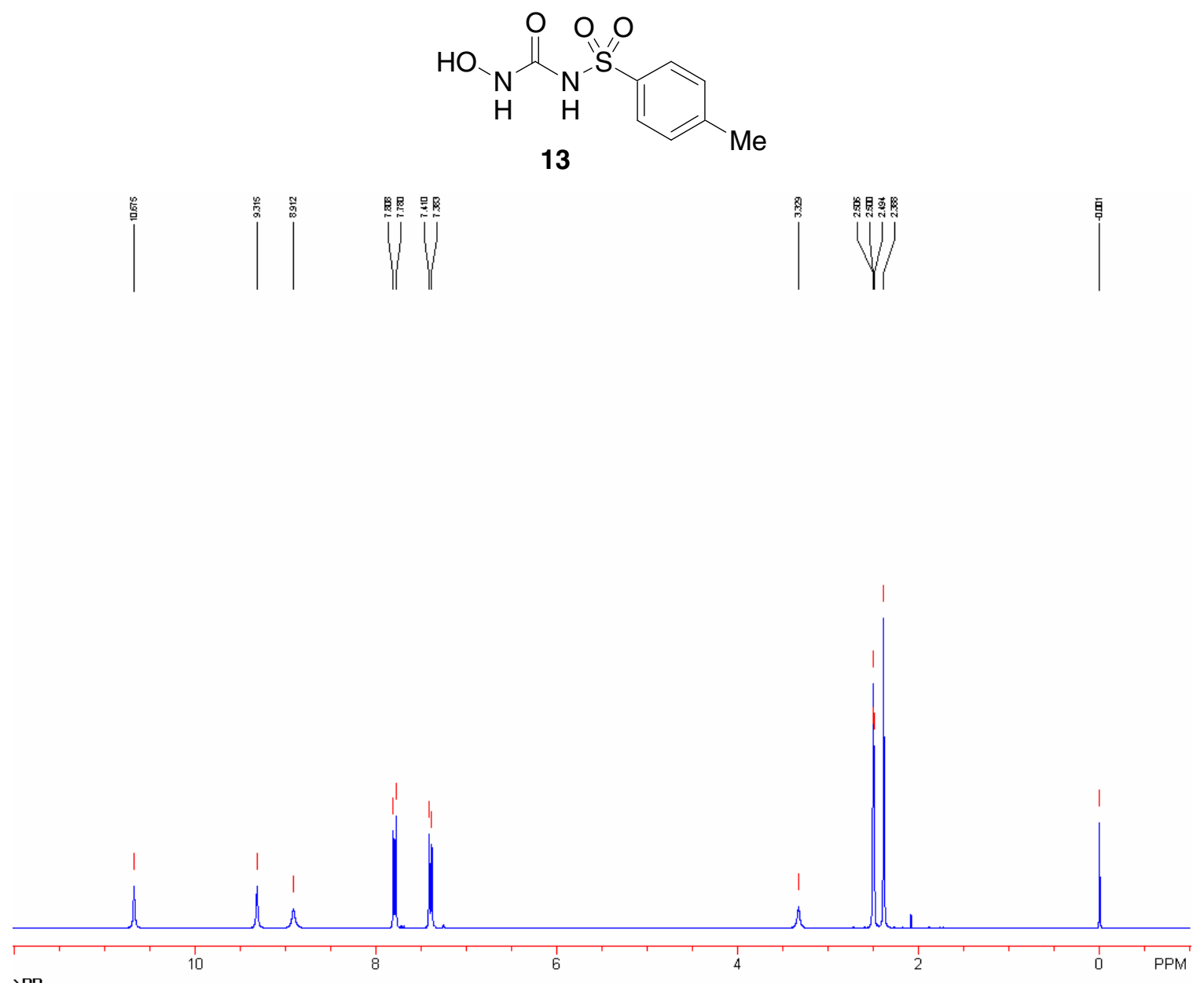
${ }^{1} \mathrm{H}$ NMR spectra of $\mathbf{1 4}\left(\mathrm{d}_{6}\right.$-DMSO, $\left.300 \mathrm{MHz}\right)$.
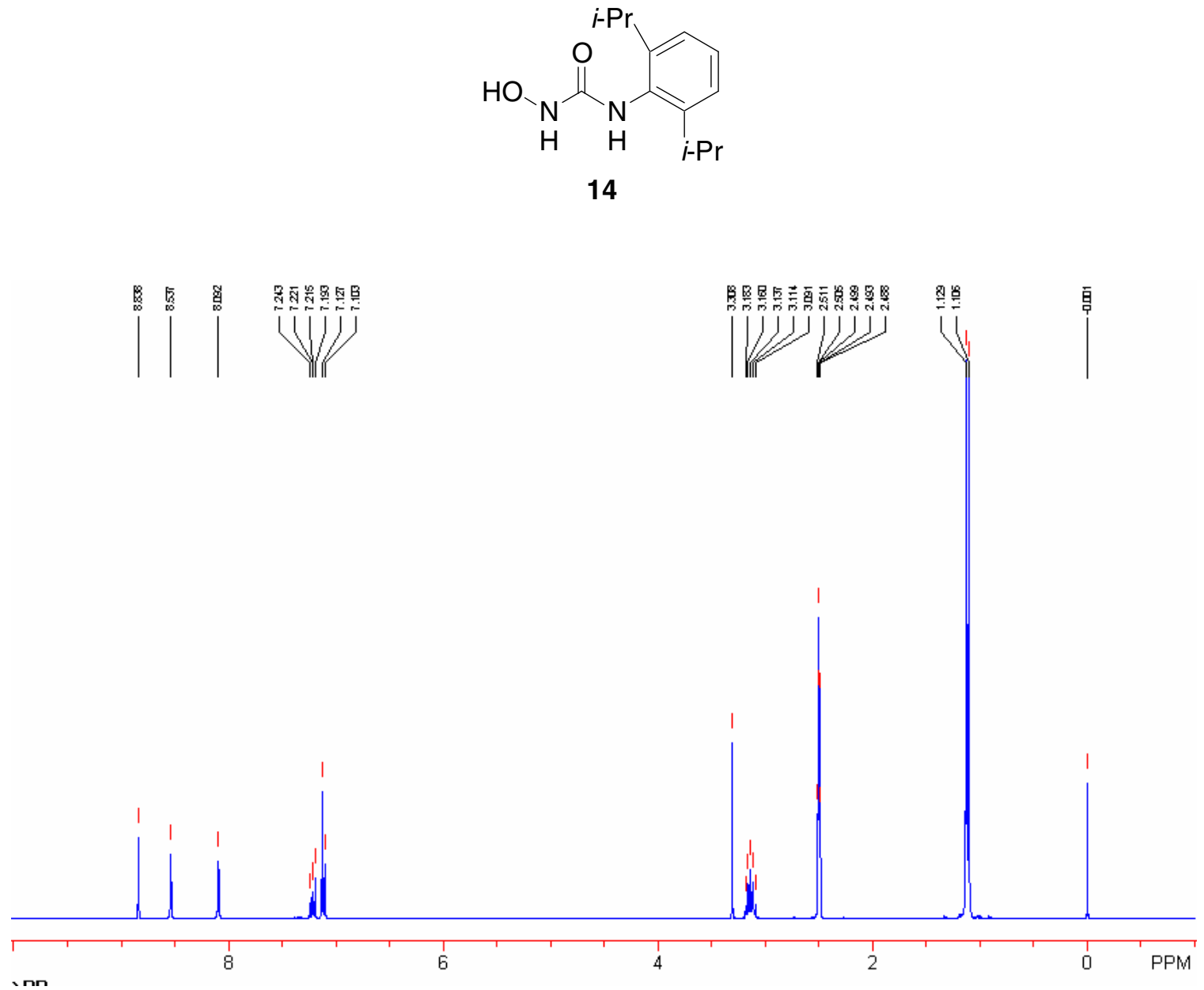
${ }^{1} \mathrm{H}$ NMR spectra of $\mathbf{1 5}\left(\mathrm{d}_{6}\right.$-DMSO, $\left.300 \mathrm{MHz}\right)$.
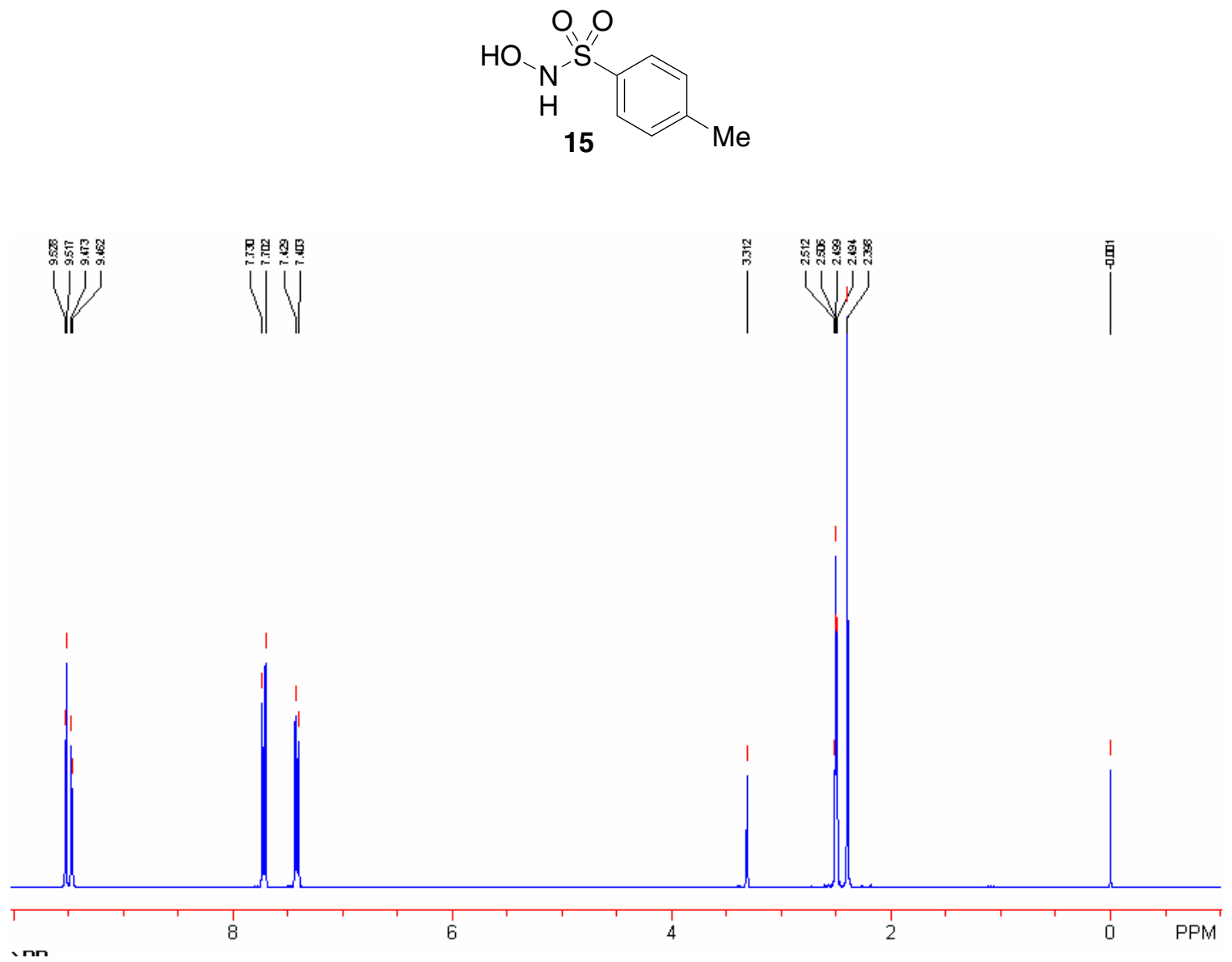
${ }^{1} \mathrm{H}$ NMR spectra of $\mathbf{1 6}\left(\mathrm{CDCl}_{3}, 300 \mathrm{MHz}\right)$.

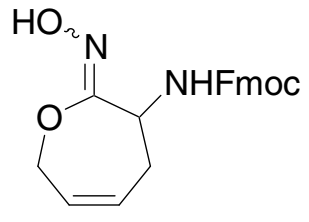

16

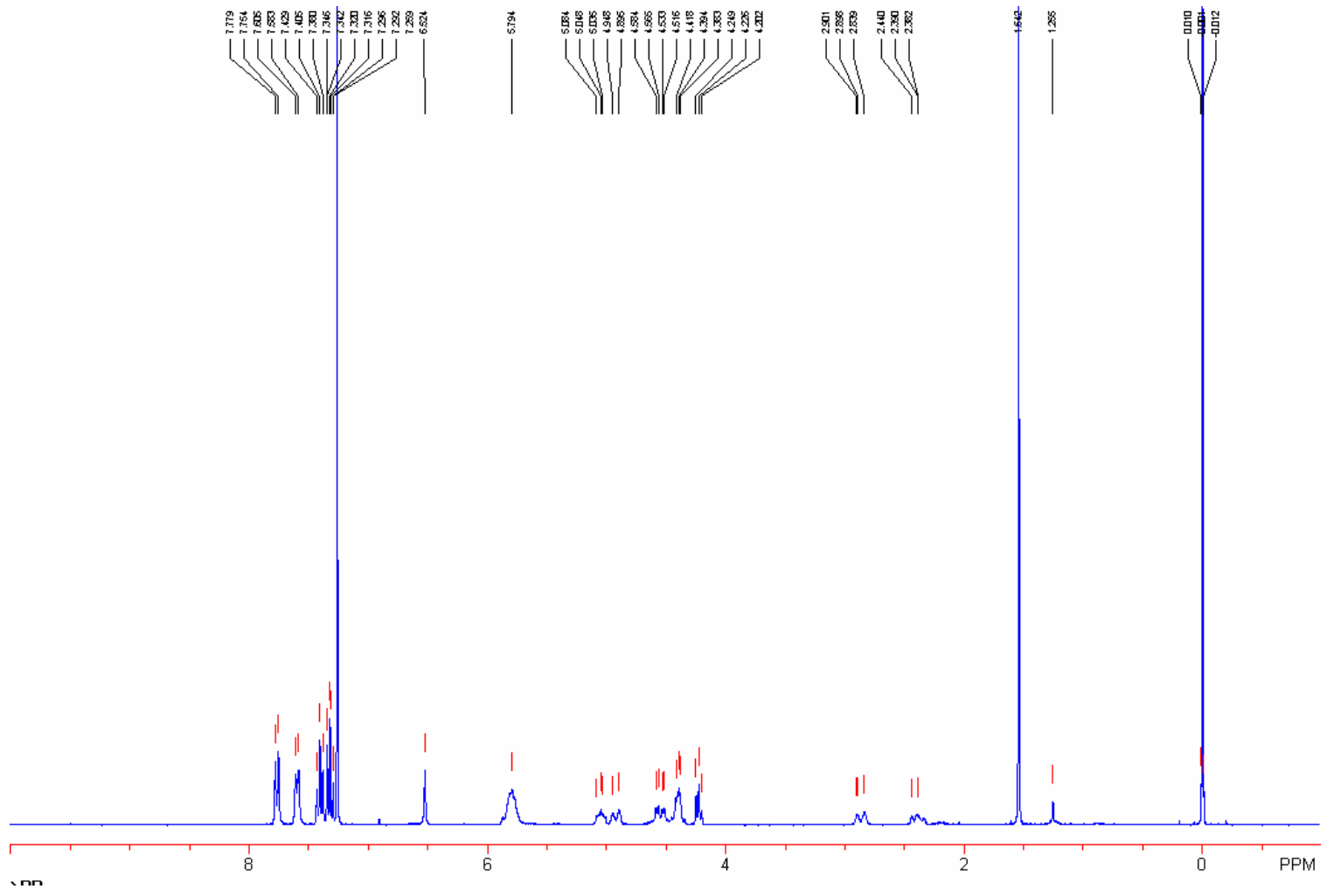


${ }^{1} \mathrm{H}$ NMR spectra of $21\left(\mathrm{CDCl}_{3}, 300 \mathrm{MHz}\right)$.
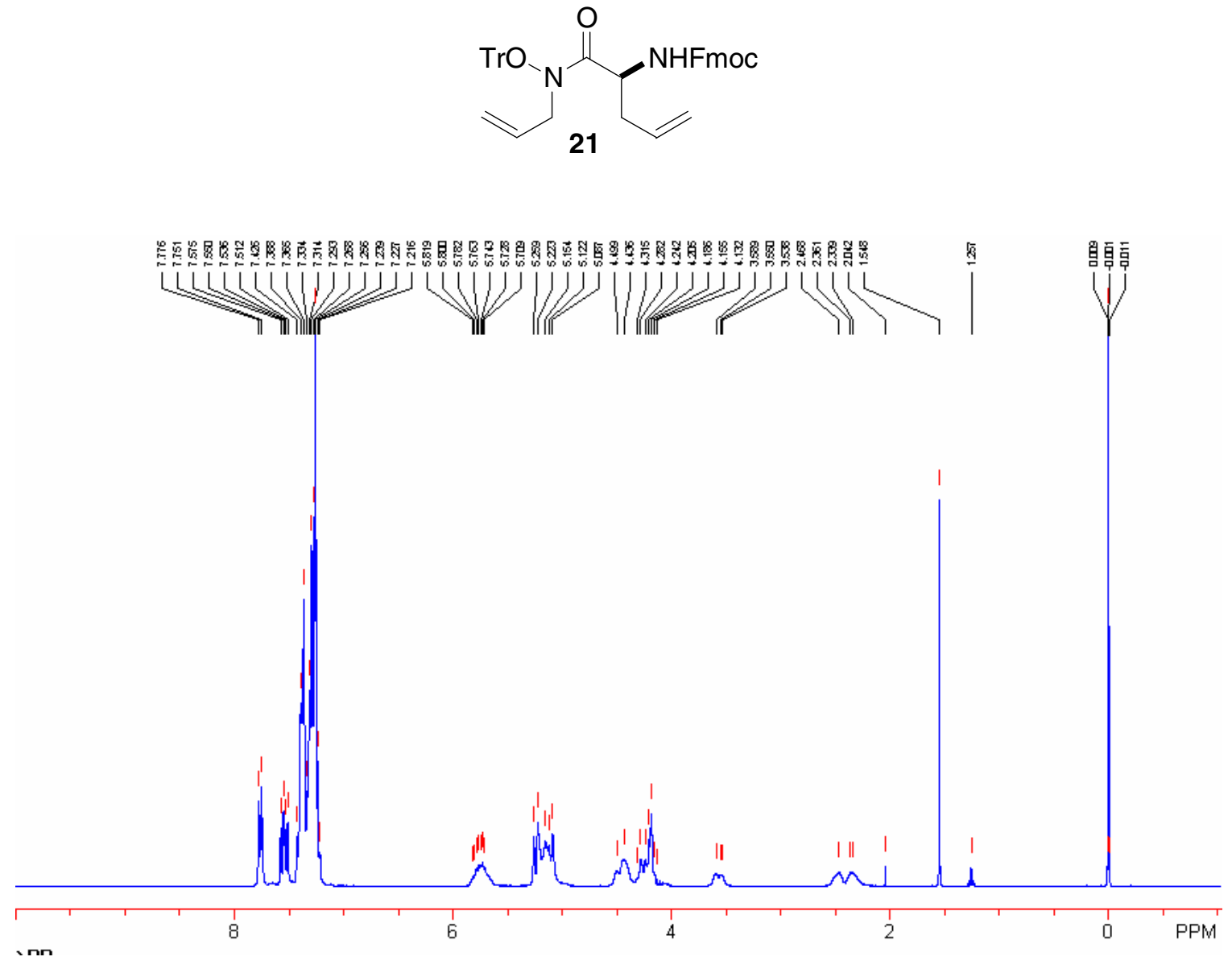
${ }^{1} \mathrm{H}$ NMR spectra of $22\left(\mathrm{CDCl}_{3}, 300 \mathrm{MHz}\right)$.

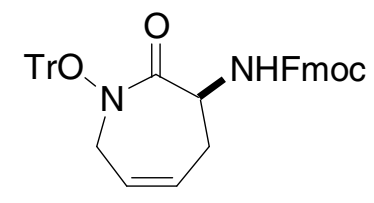

22

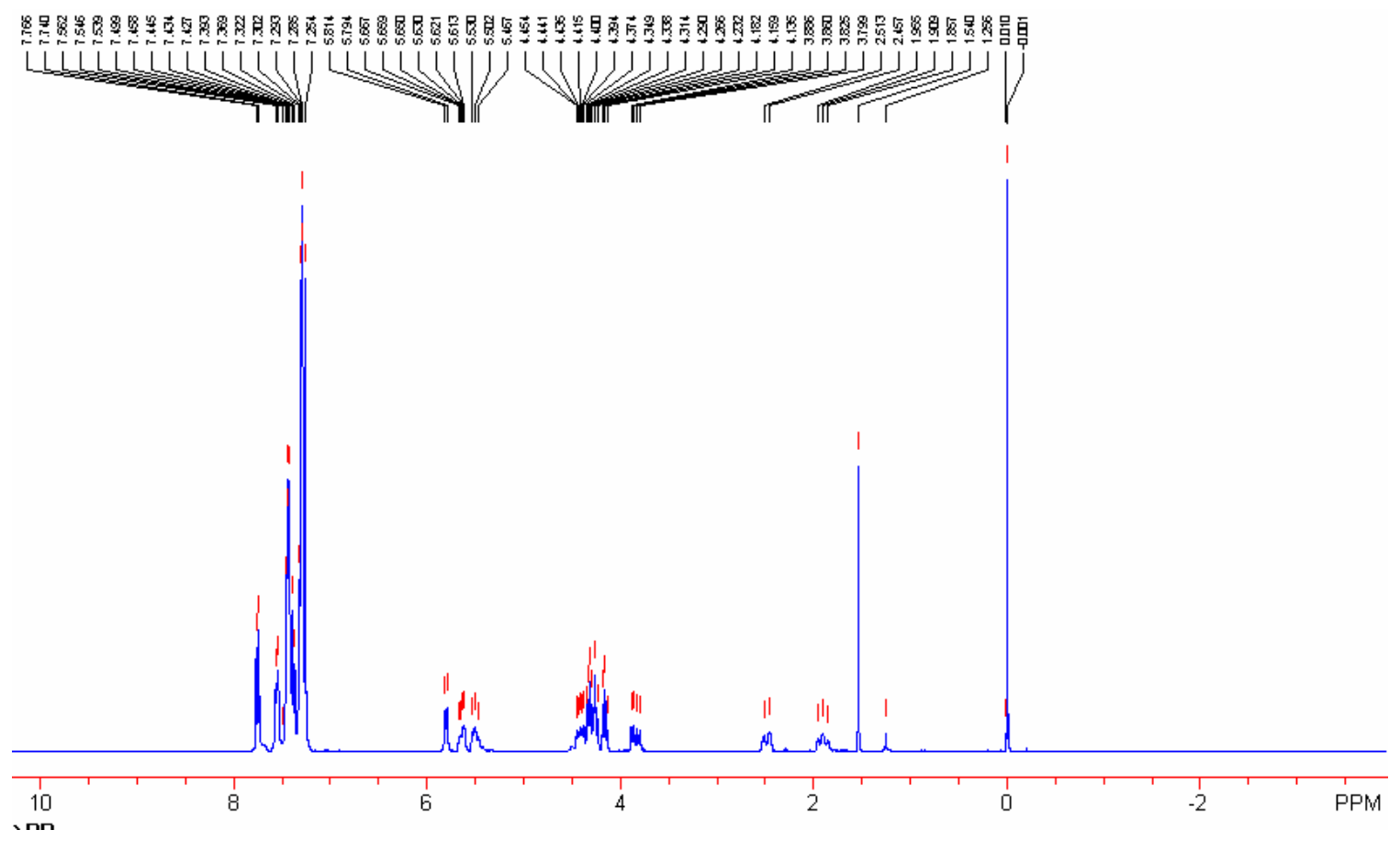


${ }^{1} \mathrm{H}$ NMR spectra of $24\left(\mathrm{CDCl}_{3}, 300 \mathrm{MHz}\right)$.

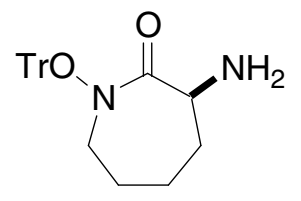

24

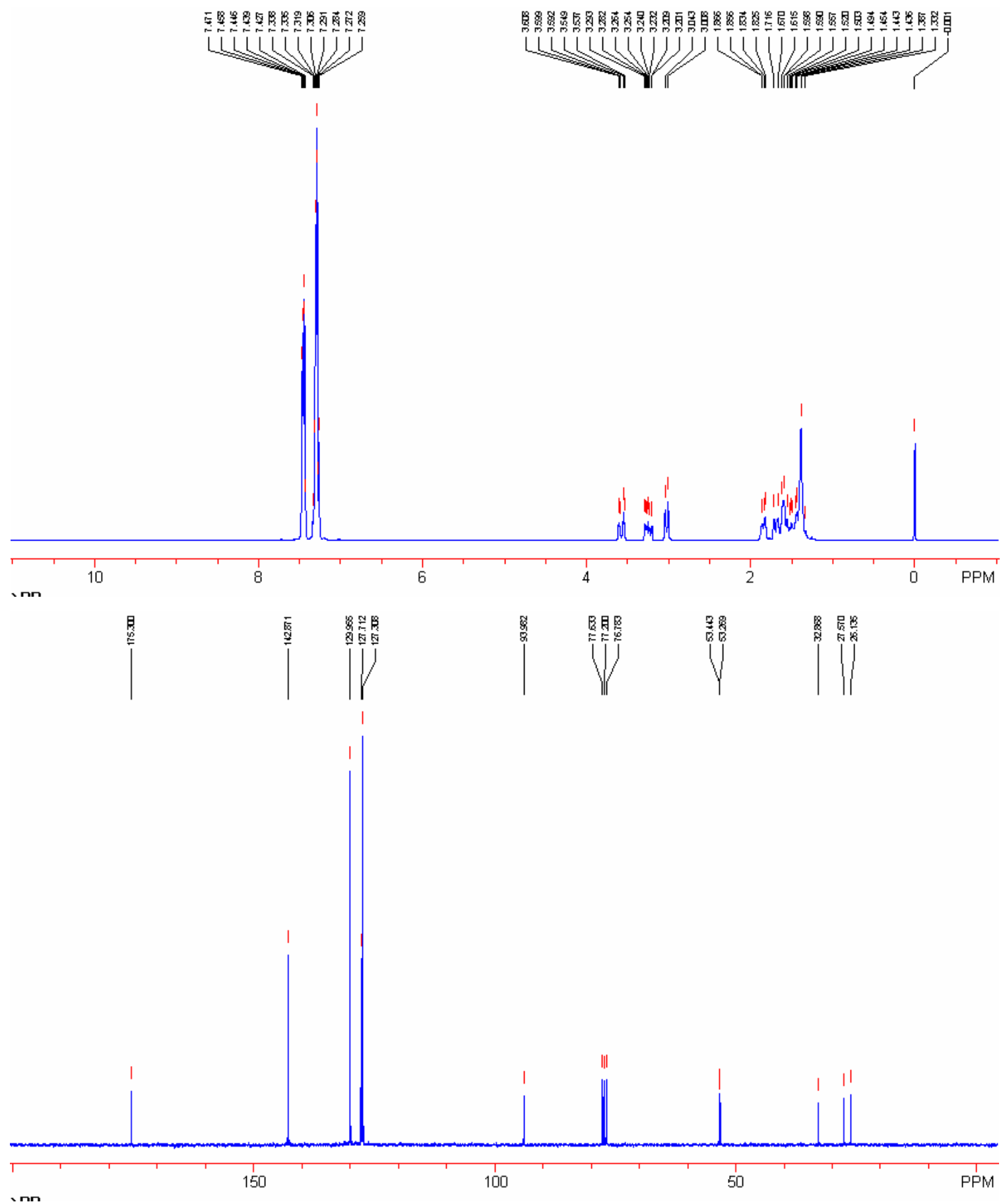


${ }^{1} \mathrm{H}$ NMR spectra and ${ }^{13} \mathrm{C}$ NMR spectra of $\mathbf{2 5}\left(\mathrm{CDCl}_{3}, 300 \mathrm{MHz}\right)$.<smiles>CCCCN1CCCCC(NC(=O)CC(C)O)C1=O</smiles>

25

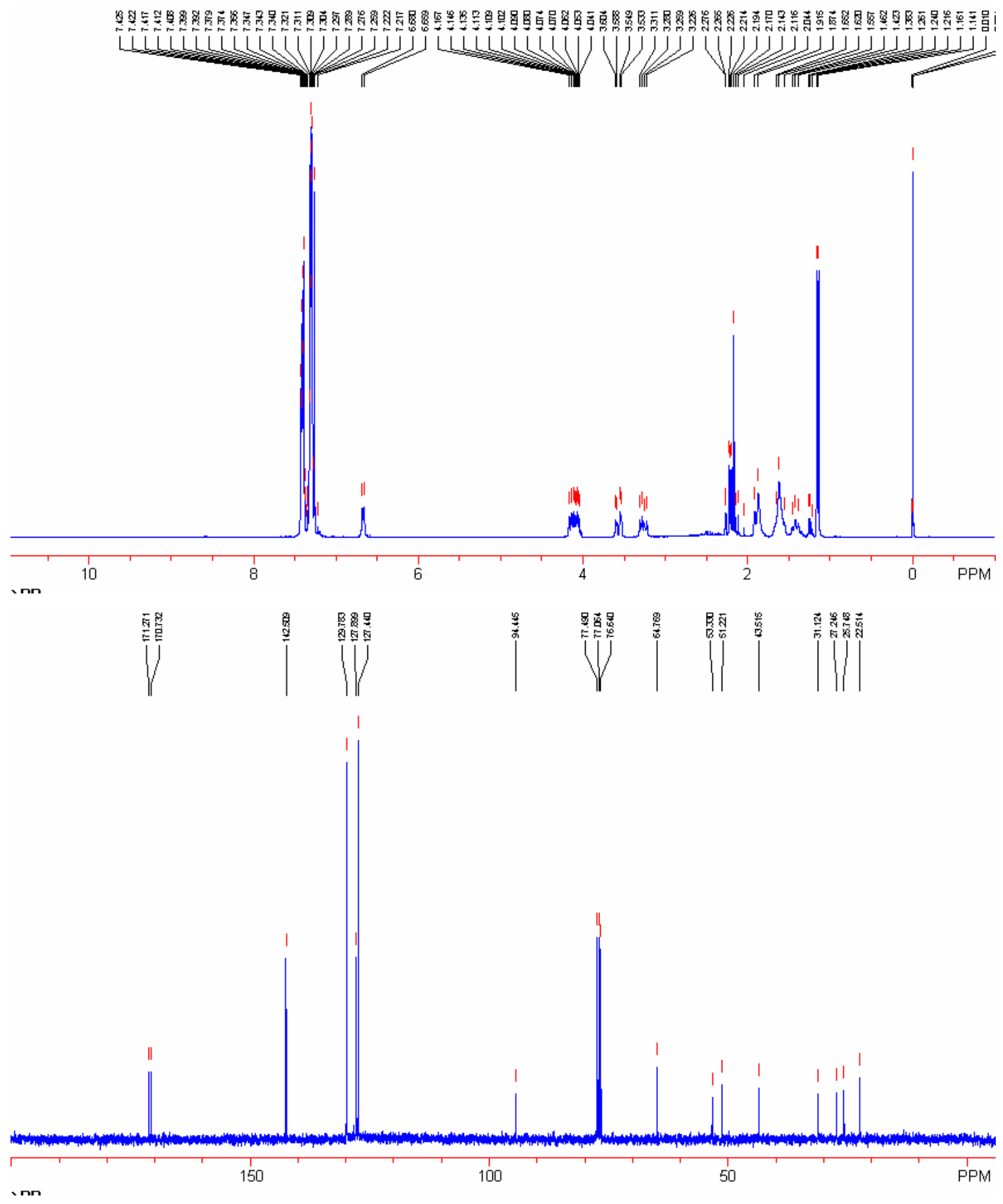


${ }^{1} \mathrm{H}$ NMR spectra and ${ }^{13} \mathrm{C}$ NMR spectra of (-)-Cobactin $18\left(\mathrm{CDCl}_{3}, 300 \mathrm{MHz}\right)$.

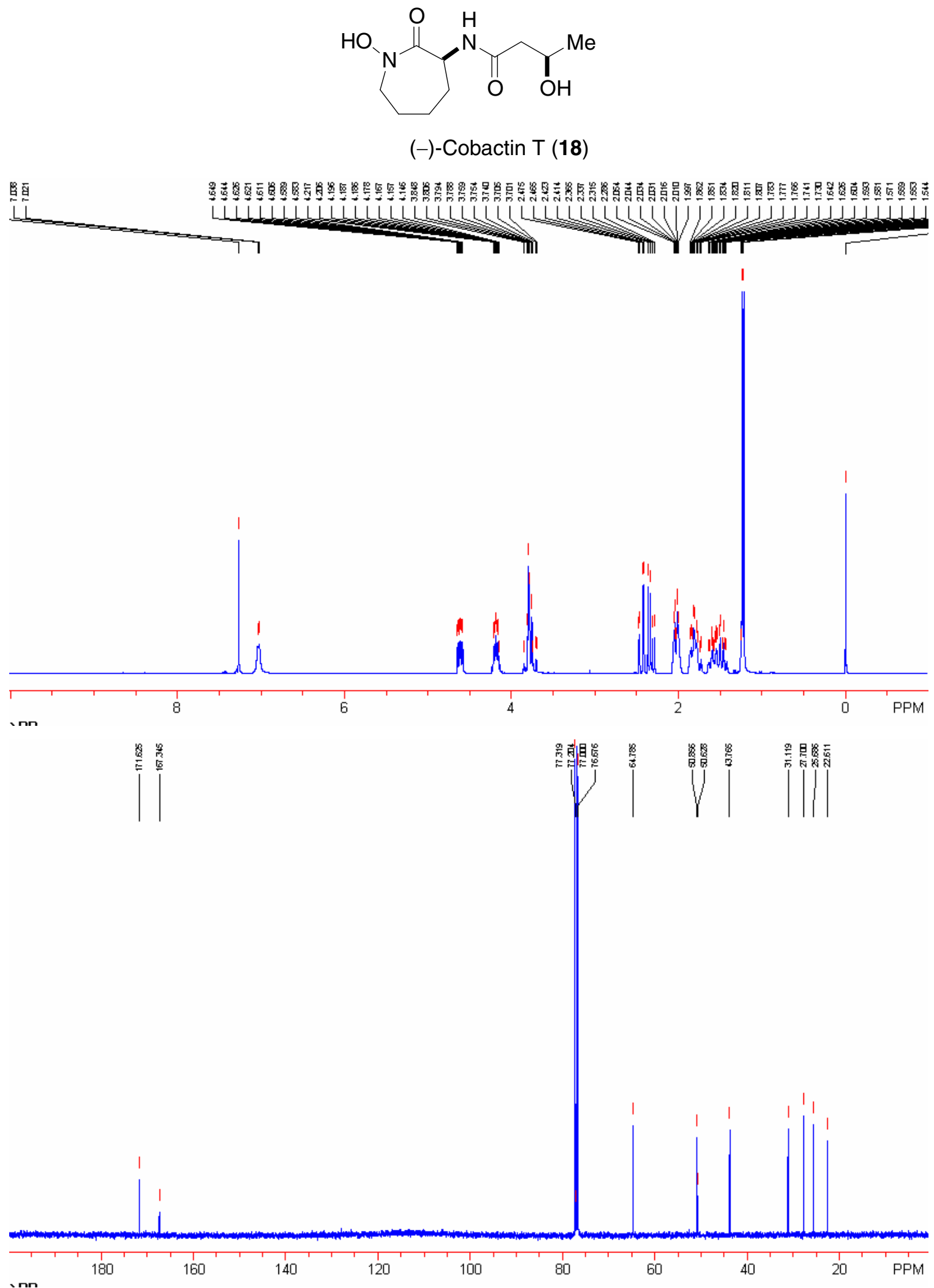

